\title{
Literatura expandida en el dominio digital
}

2. CLAUdia KOZAK / Universidad de Buenos Aires - CONICET / ckozak@filo.uba.ar

\section{Resumen}

El artículo toma como punto de partida la noción de literatura expandida, que permite leer diversos modos en que, al menos desde inicios del siglo $\mathrm{xx}, \mathrm{y}$ con fuerte impacto en décadas recientes, una zona de la literatura se ha volcado fuera de sí. Sin desdeñar la noción de expansión implicada en la vida misma como terreno de experimentación y experiencia literaria, el texto focaliza en una literatura expandida como apertura y desplazamiento hacia otros lenguajes — más allá del verbal- y otros medios y soportes — más allá del libro—; en particular en relación con la literatura digital latinoamericana. Asimismo, se plantea un breve recorrido histórico y una propuesta crítica para abordar este tipo de literatura que desafía los hábitos de la crítica. Esta propuesta crítica implica a su vez una mirada latinoamericana, para la cual el espesor semántico de la metáfora dominio digital - tanto dominio web como dominación digital- sirve de anclaje.

Palabras clave: literatura expandida $\cdot$ literatura digital $•$ fuera de sí $\cdot$ Latinoamérica $\cdot$ dominio digital

\section{Abstract}

This essay takes as a point of departure the notion of expanded literature, which enables reading a literary transit out of bounds, at least since the beginning of $20^{\text {th }}$ century and, in particular, in recent decades. Even if the idea of expansion could be understood in relation to life itself as a territory for literary experience and experimentation, the text focus on an expended literature as displacement and openness toward other languages — beyond verbal - and other media and supports — beyond the book-. In particular, the text deals with digital literature as a form of expanded literature. The essay poses a brief historical approach and suggests how to read a kind of literature that defies literary criticism habits. At the same time, this approach implies a Latin American perspective, for which the semantic density of the metaphor digital domain - meaning web domain and digital domination - acts as an anchor.

Key words: expanded literature $\cdot$ digital literature $\cdot$ out of bounds $\cdot$ Latin America $\cdot$ digital domain 


\section{Expandida}

La noción de literatura expandida resulta sugerente, aunque no del todo explicativa. Su amplitud y hasta vaguedad sugiere mundos posibles para la literatura en épocas de su mutación. Sugiere, incluso, porvenires que nos animan a seguir diciendo literatura, aun en la incerteza. Siguiendo a Borges, sabemos desde hace tiempo que la «literatura es un arte que sabe profetizar aquel tiempo en el que habrá enmudecido, y encarnizarse con la propia virtud y enamorarse de la propia disolución y cortejar su fin» (1932:205). Con todo, a veces necesitamos rodear tentativamente el vértigo de la sugerencia para explicarnos. De allí que, en este caso, plantearé en particular una noción de literatura expandida que se despega de otras maneras de entenderla, si bien mantiene con ellas parentescos varios.

$\mathrm{El}$ recorte que propongo asocia la expansión literaria específicamente a la literatura digital, y deja en segundo plano otras posibilidades: por un lado, la del tránsito de la literatura entendida como obra, o incluso texto, a la literatura entendida como práctica (Pauls); por otro lado, la del fuera de campo (Speranza 2006) que permite comprender la vinculación de la literatura con otros lenguajes y medios - el cine por ejemplo- pero sin salirse de los contornos del lenguaje, el medio y el soporte que durante al menos quinientos años se homologó a la literatura, es decir, el lenguaje verbal asociado al libro (Steiner 1978, 1990); por último, la del tránsito de la palabra y el objeto literarios hacia las artes visuales en un sentido amplio, pero casi como punto de llegada - desde la pintura hasta las instalaciones, por ejemplo_- En este último caso, se trata de una literatura expandida que, aunque plantea la noción de hibridación entre literatura y artes visuales, se comprende mejor en realidad al interior del sistema de las artes visuales, tal como la trabaja por ejemplo Ana Pato en su análisis de la obra de Dominique González Foerster. ${ }^{1}$

Antes de que expandida fuera una condición atribuida a la literatura, la noción se aplicó a otras zonas de las artes, en particular al cine y la escultura. Más allá de que en muchas de las prácticas de las vanguardias de principios del siglo xx la mixtura de lenguajes y medios se hizo presente de diversas formas, y por lo tanto cierta difuminación y expansión de los límites entre disciplinas artísticas, el término expandido adquirió notoriedad hacia fines de los años sesenta, y en particular desde 1970 con la publicación en Estados Unidos del libro Expanded Cinema de Gene Youngblood. ${ }^{2}$ Allí el autor se basaba en la noción de lo expandido no sólo, o tanto, para dar cuenta de las derivas de lo cinemático desde el fílmico al video y a lo computacional, o de diversas formas de intermedialidad como por ejemplo la mixtura de cine y teatro o la migración del cine desde el plano de la pantalla en sala hacia diversos modos de tridimensionalidad sino que, muy especialmente, comprendía todo esto como parte de una conciencia expandida. Una red intermedial que para el autor evidenciaba un modo de sacar la conciencia humana fuera de la mente y prometía ser portadora de nuevos mensajes al extender las capacidades comunicativas de los seres humanos. Desde entonces, esta noción se ha diseminado para dar cuenta también del contacto entre cine y artes visuales, siendo la galería de arte como espacio y la instalación como formato, algunas de 
las variables a tener cuenta. Así lo desarrollan por ejemplo Philippe Dubois y otros autores (20I0a, 20IOb) al utilizar la noción asociada de cine extendido. En la Argentina, Jorge La Ferla ha reflexionado también sobre las derivas del cine expandido como un cine después del cine.

Y en el campo de la escultura es en general el muy citado artículo de Rosalind Krauss, «La escultura en el campo expandido» (1979), el texto que de algún modo difunde la noción de lo expandido para dar cuenta de un estado particular del arte contemporáneo desde fines de los años sesenta en el que la concepción tradicional de escultura como monumento y la modernista de escultura como negatividad del monumento -implicando un vacío en relación con el lugar de emplazamiento y una fuerte autorreferencialidad - se expande hacia el paisaje y la arquitectura, conformando un nuevo campo lógicamente expandido, en el que sobresale el elemento lógico complejo en el que la escultura puede ser a la vez paisaje y arquitectura, pero también a la vez tanto paisaje y no-paisaje, como arquitectura y no-arquitectura, en contra de la oposición de pares binarios de la escultura modernista que la autora entiende definida por el campo del no-paisaje y no-arquitectura.

Aun así, las conceptualizaciones en torno del cine expandido y de la escultura expandida surgieron históricamente en condiciones culturales específicas en los años sesenta del siglo xx. Y la literatura que se desborda de su propio lenguaje y materialidad se ha dado desde mucho antes en paralelo a - pero en forma discontinua- la historia hegemónica de la literatura en su período moderno, es decir, en el tiempo histórico en que literatura se definió en tanto tal asociada a ciertos modos de leer - la lectura en silencio-, ciertos espacios - la biblioteca particular-y ciertos objetos — los libros- (Steiner 1990). Por ejemplo, del Tristram Shandy de Laurence Sterne en el siglo xviII a Un coup de dés de Stéphane Mallarmé en I897 y de allí a toda la poesía visual hasta el presente. Señalo aquí solamente la expansión de la literatura en el período letrado y libresco por antonomasia, esto es también, el que se vincula con la autonomía relativa de la esfera del arte en sentido general en la cultura moderna (Bürger), y por extensión, de la esfera literaria, más allá de que se pueden rastrear hibridaciones entre palabra, imagen y sonido yendo mucho más atrás en la historia. Lo hago porque no cabría quizá aplicar la noción de literatura expandida para los casos pre-modernos, en tanto no se puede pensar para aquellos contextos un confinamiento a partir del cual la literatura se expandiría.

¿Por qué entonces recurrir a un término que nace hacia fines de los años sesenta para el cine y la escultura si la literatura expandida puede encontrarse en distinta medida a lo largo de la Modernidad? Sucede que el impulso de expansión se acelera desde los años sesenta del siglo xx en adelante, por lo que el uso del término funciona un poco a la manera en que Borges entiende lo kafkiano en «Kafka y sus precursores» (1952). Esto es, somos capaces de ver que hubo expansiones de la literatura avant la lettre, porque desde la última parte del siglo xx la literatura expandida comenzó a proliferar y rodearnos de modo más evidente. 
De todas maneras, literatura expandida no es un término que tenga fecha cierta de nacimiento y, como señalé al comienzo de este artículo, sus acepciones son también variadas. Si bien hay quienes atribuyen a ensayos publicados hace pocos años haber acuñado esta expresión, en realidad se ha venido usando con alguna frecuencia en los últimos diez o quince años, y con probabilidad desde bastante antes. ${ }^{3}$

Ya en Escrituras nómades (2004) Belén Gache, quien más adelante adoptaría el término de literatura expandida en distintos escritos y proyectos artísticos, traza un recorrido histórico exhaustivo de las derivas de la escritura en una perspectiva cercana a la que aquí propongo, en particular en relación con las secciones del libro que recorren «la unión entre diferentes sistemas semióticos (lingüístico, visual y fónico)» (Gache 2004:II) y las maneras no convencionales de tratamiento del signo lingüístico y su materialidad. La literatura digital como expresión de una literatura expandida, de la que trataré a continuación, se instala en efecto cómodamente en ese recorrido ya que en gran medida trabaja en el cruce de palabra, imagen, sonido, movimiento y código informático en contextos de dominio digital.

\section{Digital $^{4}$}

La literatura digital es un tipo de literatura expandida, por lo general multimedia, que evidencia un alto grado de implicación — aunque no exclusiva - del lenguaje verbal con función poética, inscribiéndose marginalmente en la institución literaria a partir de un diálogo más o menos específico con la historia literaria en general, y con la literatura tecno-experimental en particular. A diferencia de la literatura asociada al medio libro, es literatura generada en/por/desde/hacia dispositivos electrónicos, actualmente digitales, es decir, por fuera de medios electrónicos analógicos (la radio, la televisión, el video analógico grabado en cintas magnéticas, por ejemplo). Literatura programada en código binario a través de la creación y uso de diversos software y experimentada en vinculación con interfaces digitales. No es literatura digitalizada, como traslado de textos desde el medio impreso a la pantalla de una computadora, sino nacida digital y en cuyos procedimientos es intrínseca la creación y utilización del código digital informático.

El fuerte grado de implicación del lenguaje verbal con función poética, y su diálogo con la literatura institucionalmente considerada como tal, es lo que especifica a esta práctica en relación con las artes digitales en sentido amplio, en las que lo verbal podría no tener relevancia. Claro que, por su carácter multimedia, las artes electrónicas digitales invitan a difuminar las lindes entre lenguajes, lo que viene desde hace tiempo empujando a las distintas disciplinas artísticas a un corrimiento de límites, a una expansión. Y sin embargo, me interesa ponderar aquí, en este concierto, el espacio literario expandido que persiste hasta cierto punto en tanto literario.

Dado que se trata de un fenómeno en proceso de consolidación, aun cuando surgió en los años cincuenta del siglo xx, se suelen dar para esta práctica diversas denominaciones: ciberliteratura, infoliteratura, literatura electrónica, literatura digital, literatura computacional, literatura ergódica. ${ }^{5}$ 
En sentido cronológico, las primeras realizaciones de literatura digital se integran a lo que se conoce como literatura generada o, directamente, generadores de texto. ${ }^{6}$ Si se dice literatura generada se hace hincapié en el producto, es decir, en la obra. Si se dice generadores de texto, se hace hincapié en el dispositivo de producción. ${ }^{7}$ Esa indecisión terminológica es típica de los intentos por dar con algún modo de ordenar e incluso clasificar las realizaciones de literatura digital a modo de búsqueda de géneros. Pero los criterios para definir géneros se complican, en tanto partiendo inductivamente de las diferentes obras se encuentran variables que cruzan las características del dispositivo con las de sus producciones. Por ejemplo, existen generadores automáticos de textos que producen narrativa, poesía o aun, como en el caso del primer generador conocido, Love Letters (1952) del ingeniero informático inglés Cristopher Stratchey, género epistolar. Lo más habitual, con todo, es que los primeros generadores produjeran algo que se asocia con la poesía en verso libre como los Poemas estocásticos (1959), producidos por un generador de textos creado por el alemán Theo Lutz a partir de diez tópicos tomados de El castillo de Kafka. Lo mismo puede decirse de Tape Mark I (I96I) del escritor experimental italiano Nanni Balestrini, elaborado a partir de combinaciones métricas y unidades de sentido tomadas de Diario de Hiroshima, de Michihito Hachiya; el Tao te king, de Lao Tsé y El misterio del ascensor, de Paul Goodwin. En el caso del libro Poemas V2. Poesía compuesta por una computadora (1976), del catalán Ángel Carmona, poemas generados por computadora entre I972 y 1976, la rima es una de las variables implicadas en el programa para generar los textos automáticamente.

Más adelante llegaron las experimentaciones que produjeron poesía visual a partir de la manipulación de programas informáticos. En este campo se dieron casos pioneros en Latinoamérica: por un lado, la serie de poemas IBM de Omar Gancedo publicada en 1966 en la revista Diagonal Cero de la ciudad de La Plata, dirigida por Edgardo Antonio Vigo, que consistía en tres tarjetas perforadas procesadas por una Card Intérprete IBM, que imprimía sobre el espacio medio de cada tarjeta el texto codificado en las perforaciones; y por otro lado, la serie de diez poemas de Erthos Albino de Souza, Le tombeau de Mallarmé, realizados en I972, impresos en papel por una computadora luego de la manipulación por parte del artista/ingeniero de un software para medición de temperaturas de líquidos dentro de tuberías, accesible al autor porque trabajaba para Petrobras en Brasil. Estos poemas visuales, que se visualizan en código AscII, fueron publicados en el apéndice del libro Mallarmé editado por Augusto y Haroldo de Campos y Décio Pignatari. Y en 1982 otro brasileño, el hoy muy conocido Eduardo Kac, produjo «Não!», un poema visual animado, proyectado en pantalla LED en el Centro Cultural Cândido Mendes en Río de Janeiro en i984.

En la misma línea, otros ejemplos pioneros latinoamericanos, referidos por Jorge Luiz Antonio (2008a), son «Soneto sóprávê» (1982) de Daniel Santiago con programación de Luciano Moreira, en lenguaje TAL/II; y "Universo» (I985) de João Cohelo programado en Advanced Basic Language. Hacia 1986, en Argentina, 
Ladislao Pablo Györi dio forma a uno de los fotomontajes de Grete Stern usando un software de gráficos 3D y combinándolo con un poema madi de Gyula Kosice grabado con la ayuda de un sintetizador. ${ }^{8}$

Por fuera de Latinoamérica, un caso inicial relevante en ese campo por su utilización de la computadora personal, incluido el monitor para visualización de las obras, fue el de los poemas de First Screening (1984) del canadiense bpNichol, programados en Apple Soft BASIC.

Hacia fines de los ańos ochenta se desarrollan las novelas hipertextuales en las que la historia se rearma de forma múltiple en función de la interacción de los lectores quienes al cliquear en una determinada lexía habilitan ciertos recorridos narrativos (pero no otros). Uncle Roger de Judy Malloy (versión original en BASIC de 1986-I988) y afternoon, a story de Michael Joyce (I987) son las primeras novelas hipertextuales referenciadas por los historiadores de la literatura digital. También ha sido muy leída y comentada Patchwork girl (1995) de Shelly Jackson; las dos últimas fueron elaboradas a partir del software Storyspace. En Latinoamérica, algunas de las primeras novelas hipertextuales conocidas son El primer vuelo de los hermanos Wright (primera versión hipertextual de 1996-1998) del escritor y matemático colombiano (actualmente radicado en Estados Unidos) Juan B. Gutiérrez, con diseño web de Carlos E. Herrera, y Gabriella Infinita (1998), del colombiano Jaime Alejandro Rodríguez que mutó luego en versión hipermedial, con diseño visual e interactivo de Carlos Roberto Torres, ilustraciones de Clara Inés Silva y adaptación de textos, locución y coordinación general de locución de Andrés López. Tierra de extracción, por su parte, de Doménico Chiappe - escritor nacido en Perú, que ha vivido en Venezuela y desde hace ya tiempo en España-, cuenta con diseño multimedia de Andreas Meyer y la colaboración de muchos otros artistas (músicos y artistas plásticos por ejemplo); fue iniciada como proyecto en I996, aunque su primera versión es del 2000.

Ya en el siglo Xxi aparecen experimentaciones que vinculan también a la literatura digital con el videojuego, sobre todo cuando se trata de una apropiación de las lógicas y dinámicas del videojuego a partir de un impulso literario. Algo que, a mi criterio, no tiene por qué suceder con todo videojuego. Esto sí se da, por ejemplo, en Palavrador (2006) o Liberdade (2013), obras de ambiente inmersivo en las que se realizan recorridos por espacios virtuales en los que distintos poemas van emergiendo o, mejor, se van encontrando, como parte del juego, y que han surgido en espacios de creación colectiva de los que han sido protagonistas artistas brasileños como Chico Marinho, Alckmar Luiz dos Santos, Álvaro Andrade García, entre muchos otros artistas visuales, poetas, programadores, etcétera.

De lo dicho se desprende que no es posible delimitar tipos de literatura digital solo en función de su carácter narrativo, lírico, dramático o ensayístico, al modo en que se han definido los géneros literarios tradicionalmente; sino que es preciso construir un modelo de variables cruzadas que tenga en cuenta también, además del carácter genérico, otras variables en función de: i. modalidades constructivas como conectividad (on/off line), automatismo (generatividad algorítmica/no 
generatividad), interactividad (sí/no); direccionalidad (linealidad/hipertexualidad e hipermedialidad); autoría (individual, colaborativa en producción, colaborativa en recepción); ii. lenguajes (verbal, visual, sonoro, imagen-movimiento) y iii. soportes, esto es, tipo de interfaz (computadora, teléfono móvil, tablet, pantalla en espacio público).

Un modelo tal, que he esbozado ad hoc y es altamente perfectible, permite en todo caso agrupar obras para, desde allí, analizar no tanto si una obra participa de cada una de estas características o de un género sino cómo se han dado históricamente algunos tipos de literatura digital (o cruces de variables) por encima de otros y hasta qué punto un cruce de variables determinado permite elaborar ciertos modos de ver, ciertas máquinas de percepción que, en términos bajtinianos, implicarían géneros no solo como tipos de discursos o de textos sino como formas de finalización de la realidad, como tipos de enunciados que se vinculan con ciertas zonas de la realidad y no otras, y asumen así un modo hasta cierto punto específico de acceso al sentido (Bajtin; Bajtin y Medvedev). Esto, para evitar el riesgo de la clasificación por la clasificación misma, algo que se evidencia quizá incluso más en un campo como el de la literatura digital aún en consolidación, en el que es necesario en muchas ocasiones explicar los objetos específicos a públicos no familiarizados con ellos. La clasificación resulta así un vehículo de esa explicación, simplemente para hacer accesible un catálogo de obras. Lo que podría alejarse tanto de la reflexión por los modos de ver habilitados por las obras como por la construcción de la mirada crítica en relación con su objeto.

Para dar solo un ejemplo de tipos de obras de literatura digital que habilitan modos de ver específicos, es posible sostener que las obras que presentan como modalidad la generatividad automática instalan para la literatura digital una muy fuerte impronta combinatoria probabilística — dependiente de un algoritmoque abreva en el tecno-experimentalismo constructivista de movimientos como oulipo y la poesía concreta pero que, al mismo tiempo, suele aparecer en superficie como tendiendo hacia el azar. Algo que viene insistiendo en la historia de la poesía moderna al menos desde Un coup de dés de Mallamé. La tensión entre programación-construcción y azar da así sentido general a esas obras, más allá de los sentidos particulares que podrían surgir de los textos.

Pero los sentidos particulares también tienen sentido. De lo contrario, solo estaríamos leyendo el dispositivo. Importan por ejemplo cuáles son los textos o reservorios de textos de los que se extraen las unidades mínimas combinatorias, importan las lenguas de esos textos, su carácter previamente literario o no literario. Importan finalmente los hallazgos que pudieran suscitarse en la generación automática, hallazgos que sobre todo en las obras generativas que utilizan interfaces contemporáneas — pantallas táctiles o no, mouse, auriculares - mucho tienen que ver con las decisiones de quien lee: si la obra es interactiva, por ejemplo, detener su funcionamiento cuando se cree encontrar algo que vale la pena leer es atribución que se ubica del lado de la lectura. ${ }^{9}$ Las obras, con todo, podrían poner ex profeso obstáculos para esa lectura. Característica que, como se verá más 
adelante, entiendo como uno de los modos posibles en que una zona de la literatura digital contemporánea hace un comentario al dominio de la cultura digital.

\section{Cómo se lee}

Lo que nos lleva a la pregunta por la lectura de esta literatura expandida. ¿Son las operaciones de la crítica de la literatura digital las mismas que las de la literatura de libros? La cuestión ha generado debates dentro del campo específico. Pasado el período en el que la crítica se concentraba en sensibilizar a un público no iniciado acerca de la existencia de la literatura digital —algo que de todos modos se sigue haciendo- se abren preguntas y caminos más interesantes que los del catálogo y la demostración respecto de cómo funciona el dispositivo. Apareció por ejemplo una línea crítica que sostuvo la necesidad de ir a los textos, más allá de su funcionamiento técnico. Esta línea crítica intentó una lectura textualista, que pudiera dar cuenta de cada obra en particular, por lo que tiene para decir (Koskimaa). Lo cual sigue siendo valioso a condición de que consideremos ese más allá del funcionamiento como un además de su funcionamiento o mejor, junto con su funcionamiento, ya que no resulta convincente dejar de lado que la obra no se agota en el transitorio observable y el texto por ver - conceptos de uno de los poetas y teóricos del campo, el francés Philippe Bootz (2OII) - , es decir, de su superficie fenomenológicamente aprehensible. Subiendo la apuesta, hay una corriente de literatura digital, en particular de poesía digital, tanto en producción como en recepción crítica, que hace pie en el código informático como lenguaje específico que no se puede desatender. Poesía de código, por ejemplo, es poesía escrita incluso en su superficie observable con código informático (Marino). Es decir, es el código informático lo que se presenta directamente como texto poético. Si a su vez ese texto poético es ejecutable, mejor. Lo que no sucede en muchos casos.

En el entorno anglosajón -y por extensión de dominio geopolítico dentro del campo de la teoría y crítica de la literatura digital mundial - se entiende la lectura textualista bajo el concepto de close reading, metodología de lectura crítica vinculada desde mediados del siglo xx al formalismo del New Criticism, pero que en la actualidad incluye diversos abordajes. Esta lectura resulta viable solo si se toma en cuenta la diferencialidad del texto en tanto texto digital. Como sostiene Katherine Hayles, una de las fundadoras del campo de la teoría de la literatura digital, en un artículo justamente titulado «How we read?» (20IO), si se toma en cuenta la diferencia ideológica que separa al texto impreso del digital. Ya que la sola lectura de cerca corre el riesgo de trasladar sin más un abordaje propio de la literatura impresa a la digital. Existen sin embargo lecturas, que leyendo de cerca, lo hacen no solo desde un punto de vista de la superficie textual sino también desde la propia especificidad de la interfaz. Así por ejemplo la propuesta de Alexandra Saemmer en Francia (2008) al postular su análisis retórico de poesía digital tanto en términos de figuras de superficie como en los de figuras de interfaz. Serge Bouchardon, otro poeta, programador y crítico francés, también ha trabajado en modelos de lectura de materialidades diversas que confluyen en la 
literatura digital. Destaca así la lectura de la materialidad del texto, de la interfaz y del código.

A todo esto se puede agregar la lectura ya no de cerca sino de lejos, la lectura de procesos de conjunto que se visualizan cuando leemos tomando distancia de los textos. Desde la perspectiva muy conocida y debatida de Franco Moretti (2000, 2007), la lectura distante - distant reading-, siendo más afín de la lectura sociológica, llevaría a salirse del formalismo según Moretti etnocentrista ya que - sostiene- el problema con las variadas formas de textualismo, desde el new criticism hasta la deconstrucción sería que depende de un canon relativamente pequeño (Moretti 2000:57). Lo que implica una cuestión política. En el ámbito de la literatura digital, los integrantes de ELMCIP — quienes organizan la Electronic Literature Knowledge Base - han desarrollado lecturas distantes del propio campo. Por ejemplo, la lectura que Jill Walker Rettberg (2013) realizó del corpus total de las sesenta tesis académicas sobre literatura digital producidas en todo el mundo de 1976 a 20I2, recopiladas en la base de datos de ELMCIP, resulta aclaratoria de los modos en que el campo de estudios de la literatura digital se ha constituido y permite dar cuenta de una política de la literatura digital globalizada, no solo por sus inclusiones sino también, como reconoce la autora, por sus exclusiones debido, entre otros motivos, a barreras lingüísticas y lejanías geopolíticas.

Para salvar de algún modo la estrechez de algunos de estos abordajes cuando aparecen aislados, hay críticos que están trabajando en una lectura colaborativa para la que se conforman equipos de lectura en los que cada integrante aporta sus competencias específicas: lectura de cerca, lectura de código, lectura distante (Pressman y otros).

La propuesta en la que trabajo en relación con esto es lo que llamo lectura cercana-distante-colaborativa-localizada. Se trata de una lectura que sin desatender lo que los textos nos llevan a leer en ellos — textualista o de cerca-, atiende también procesos más generales en relación con la constitución del campo, con sus géneros, su institucionalización y sus geopolíticas, y por ello es distante. Asimismo, se trata de una lectura que focaliza en las distintas capas textuales - textos de superficie, interfaces y código informático — por lo que puede plantearse como colaborativa, al menos en los casos en que una sola persona no posea las competencias suficientes para la lectura de código, algo frecuente para quienes hacemos crítica literaria. Por último, en vinculación con las ya mencionadas geopolíticas, es también una lectura desde acá, que permite leer la particular politización del campo que se produce muchas veces en Latinoamérica — pero no siempre- Con lo cual, distante y localizada no resulta necesariamente un contrasentido.

\section{En/desde Latinoamérica}

Destaco en esta línea - cuyo análisis he iniciado en algunas lecturas previas (Kozak 20I2, 20I3, 20I7a) - el impulso de politización de la práctica en relación con la habitual naturalización de procesos de modernización tecnológica y los modos en que ciertas obras de literatura digital latinoamericanas ponen en 
cuestión el desplazamiento y la migración de los lenguajes a partir de procedimientos que discuten la creación de sentido en contextos global-digitales - discutiendo hegemonías lingüísticas, enfatizando lenguajes desviados, políticas del error, tránsito de unas lenguas a otras, legibilidades amenazadas o comprometidas y sinsentidos en el entorno digital.

En cuanto a la modernización tecnológica, con la que la literatura digital está vinculada casi por defecto, me interesa leer esta literatura expandida cuando no comulga necesariamente con la novedad. Separo así la noción de novedad, asociada fácilmente a un recambio constante que sigue a menudo la lógica del reemplazo de mercancías en el mercado, de la noción de lo nuevo como experiencia de un acontecimiento (Deleuze I987a y b, Lazzarato, Agamben). ${ }^{10}$ En ese sentido, podría decirse, la mejor literatura ha tendido siempre hacia una experiencia tal. Hacia la apertura de lo radicalmente nuevo e irrepresentable, que no se deja avasallar por las novedades del día. ¿Por qué involucrarla entonces con un ámbito de producción de esas novedades como el de la cultura digital contemporánea? Porque al menos parte de la literatura digital puede leerse como un modo de intervenir, interrumpiéndolo desde dentro, el sensorium hegemónico de los dispositivos tecno-políticos que dominan la vida cotidiana de una porción importante de la población del planeta. Asumiendo así la época desde un régimen de insumisión (Brea).

Literatura expandida latinoamericana en el dominio digital significa en muchas ocasiones entonces - pero no siempre, lo repito- ese desvío en el corazón mismo del entorno, el ámbito, el territorio y la dominación digital. En la trama etimológica del dominio, que vincula territorio y poder — sabemos que el domine, señor, es quien detenta el poder en la casa y su ámbito de incumbencia-, el dominio digital se reconoce en nuestro presente como ámbito de incumbencia de la vida misma, si bien no para todos los habitantes del planeta, al menos sí para una amplia parte de los mismos. Vida que transcurre a la vez dentro y fuera de las pantallas, las redes informacionales y sociales, los territorios actuales pero también virtuales, organizados por una materialidad ubicua, aparentemente deslocalizada e inmaterial, que sin embargo tiene residencia fija en un dominio, como identificador de una posición localizada en el espacio virtual de Internet.

Para dar cuenta de esto, me detengo aquí en obras de dos artistas latinoamericanos que pueden relacionarse — al menos en parte - con la literatura expandida digital, específicamente con la poesía digital. Por un lado, algunas obras de Eugenio Tisselli — poeta, net.artista y programador nacido en México, con base de operaciones en Barcelona y desplazamientos varios que incluyen un retorno de un par de años a México o trabajo de arte/investigación/intervención en Tanzania-. Por otro lado, algunas obras de Gabriela Golder —artista asociada habitualmente a las artes audiovisuales y el formato instalación, nacida en la Argentina, con varias residencias artísticas en otros países-. Debido a que Golder es más conocida en el campo del video y las instalaciones, no siempre se ha reparado en que muchas de sus obras exhiben una impronta y un impulso literarios de peso. 
Uno de los primeros trabajos tecnopoéticos de Eugenio Tisselli, midipoet, desarrollado entre 1999 y 2002, es un programa informático de manipulación de imagen y sonido en tiempo real que permite componer e interpretar diverso tipo de obras, entre ellas, poesía digital. De modo general puede decirse que el programa - como muchas de las otras obras de Tisselli y de gran parte de los artistas involucrados en el movimiento net.art - se plantea como una herramienta de distorsión del imaginario digital al uso, al introducir «el virus de lo absurdo, de lo lento, lo inútil» (Tisselli 20I5b). Claro que para que esto sea posible es preciso intervenir directamente en el programa, utilizando también código informático, un tipo de lenguaje que siempre implicará un grado de eficiencia y utilidad aún en la inutilidad. Tisselli reformula esta paradoja apelando a nociones oulipianas:

Decía Raymond Queneau, cofundador del movimiento [oulipo]: «sólo se puede mandar al lenguaje obedeciéndolo». Aquí hay una resonancia clarísima con el «mandar obedeciendo» de los zapatistas: todos somos subcomandantes del lenguaje. Pero lo que este mandar al lenguaje obedeciéndolo es, según yo, que el poeta solamente puede subvertir o sabotear el lenguaje conociendo a fondo sus reglas, sus constricciones. De manera correspondiente, el poeta digital puede hacer corto circuito en la máquina tecnolingüística si conoce sus códigos a la perfección.

En otra de sus obras, PAC. Poesía asistida por computadora (2006), Tisselli trabaja también en relación con estas políticas de la distorsión, ofreciendo herramientas para la creación poética propia o ajena. Se trata de un programa en el que a partir de versos semilla se generan sustituciones lexicales remotas que dan origen a nuevos versos (Fig. I $P A C$-ejemplo de verso semilla; Fig. 2 PAC-ejemplo de nuevo verso).

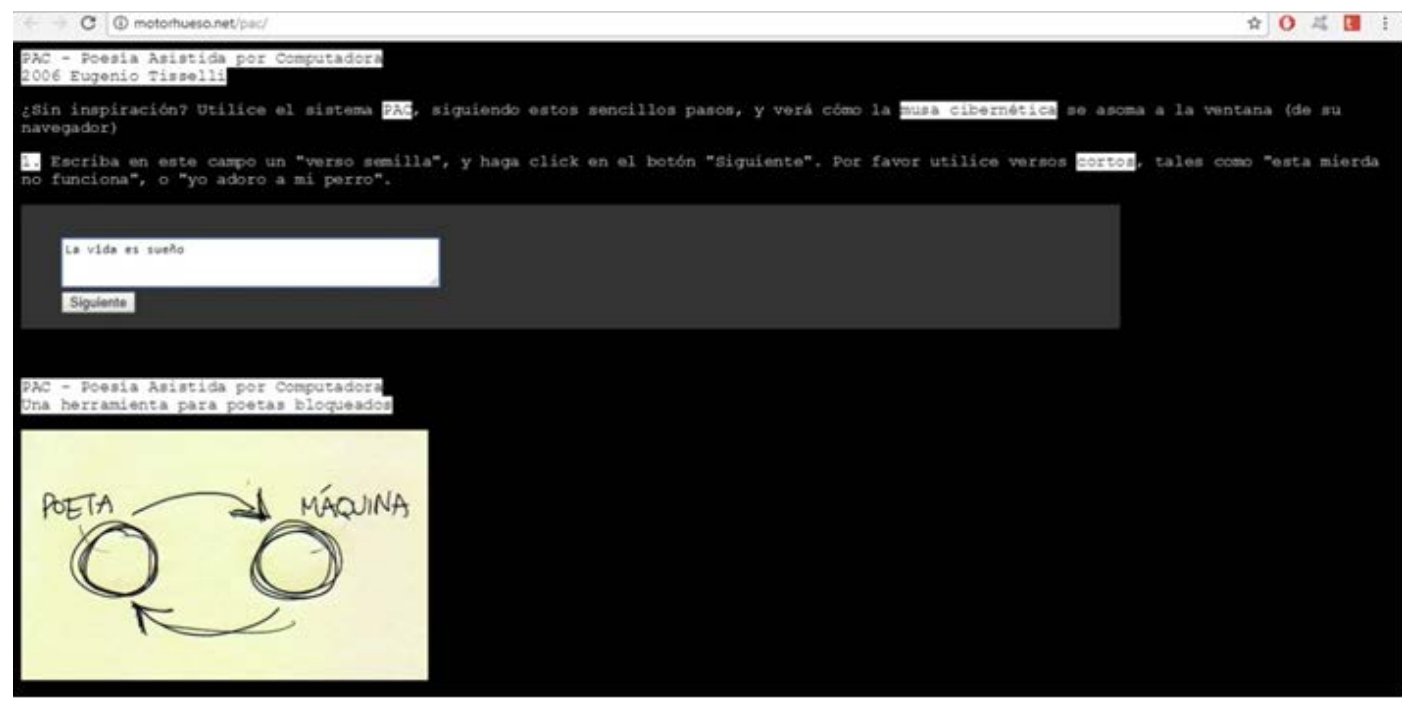




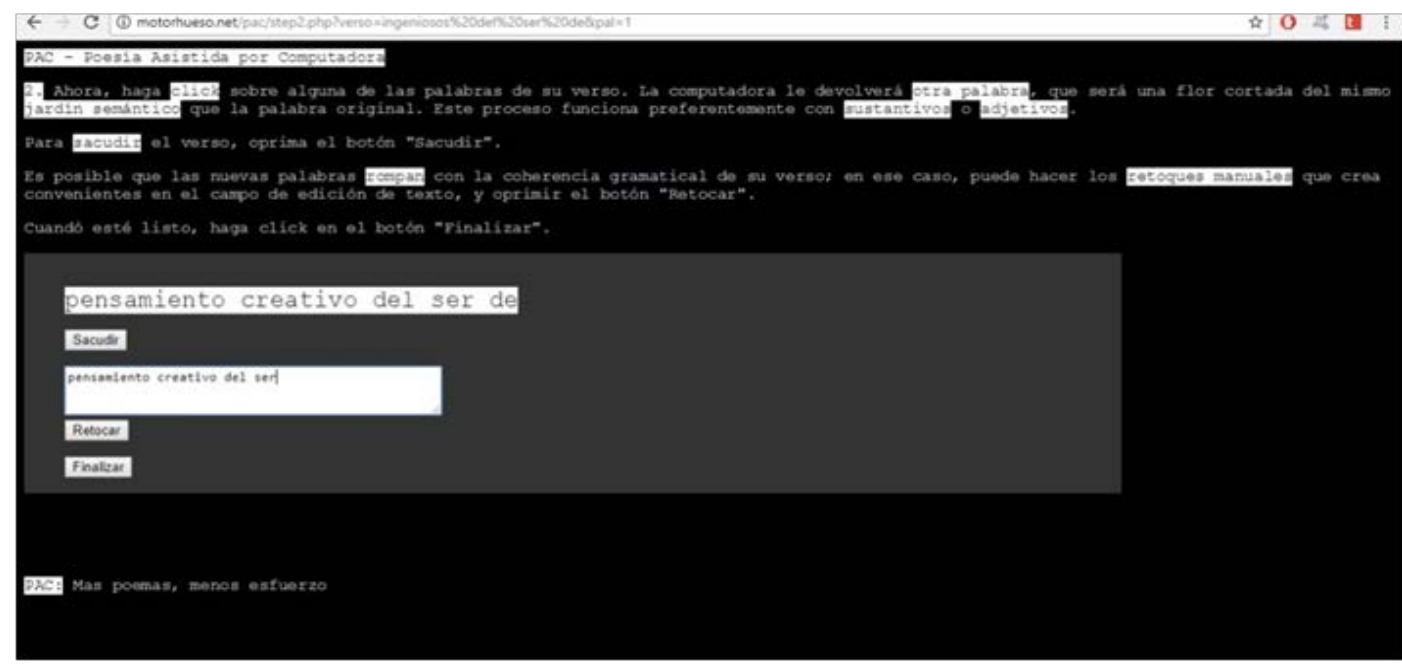

El programa ha sido desarrollado en tres versiones lingüísticas: español, catalán e inglés. Utilizando dicho programa, Tiselli elaboró su libro de poemas El drama del lavaplatos, publicado en papel en 20ı0, que lleva en sus primeras páginas la siguiente explicación:

I. El poeta introdujo un verso inicial (verso semilla)...

2. La computadora tradujo el verso semilla al inglés, usando un traductor automático alojado en alguna parte de Internet...

3. La computadora intentó sustituir cada palabra por un sinónimo tomado de algún diccionario en alguna parte de Internet...

4. La computadora tradujo de nuevo al castellano siguiendo el mismo procedimiento que en el paso 2.

5. El poeta ajustó el poema manualmente cuando aparecían incoherencias gramaticales...

Más allá del aspecto lúdico involucrado, que lleva a Tisselli a promocionar $P A C$ como el necesario remedio cuando las musas nos abandonan, la obra se inscribe en genealogías como las de los generadores automáticos de texto, el apropiacionismo y las escrituras no-creativas (Goldsmith). Pero además, y sobre todo, refuerza una concepción política de la poesía digital que discute supuestos atributos de la cultura online como transparencia y horizontalidad en las relaciones de poder. Dado que los traductores automáticos no son necesariamente confiables, la obra exhibe todo el peso de una incerteza que pretende habitualmente pasar por cierta. Que el traductor automático utilizado esté además «alojado en alguna parte de Internet», nos habla de nuestra frecuente imposibilidad de rastrear las rutas que transitan los contenidos que consumimos online. Y aunque el español sea una lengua muy transitada en Internet, en comparación con lenguas mucho más acotadas en cuanto a comunidad de hablantes, no deja de ser importante que en la versión de $P A C$ en inglés —en realidad CAP. Computer Aided Poetry - los pasos 2 y 4, es decir, la intervención del traductor automático remoto, queden elididos. Con lo cual, en cualquier idioma que no sea el inglés la obra gana en distorsión como comentario adicional a las políticas lingüísticas globalizadas. 
Si bien midipoet y PAC fueron desarrolladas por Tisselli hace ya tiempo, siguen vigentes y son usadas en distintos proyectos que lleva adelante. Uno de los más recientes, por ejemplo, denominado La tiranía del código (2015) involucra a ambas. La obra plantea una mirada sobre el artefacto urbano contemporáneo entendido como un entramado de algoritmos digitales y máquinas interconectadas. Así, videos grabados en caminatas por la ciudad de México son manipulados usando midipoet y combinados con textos que surgen de la aplicación de $P A C$, leídos por dos voces robóticas. En el sitio web del artista se puede ver uno de los videos/textos distorsionados, pero también es posible descargar los programas para intervenir la obra con nuevas distorsiones (Fig. 3 La tiranía del código).

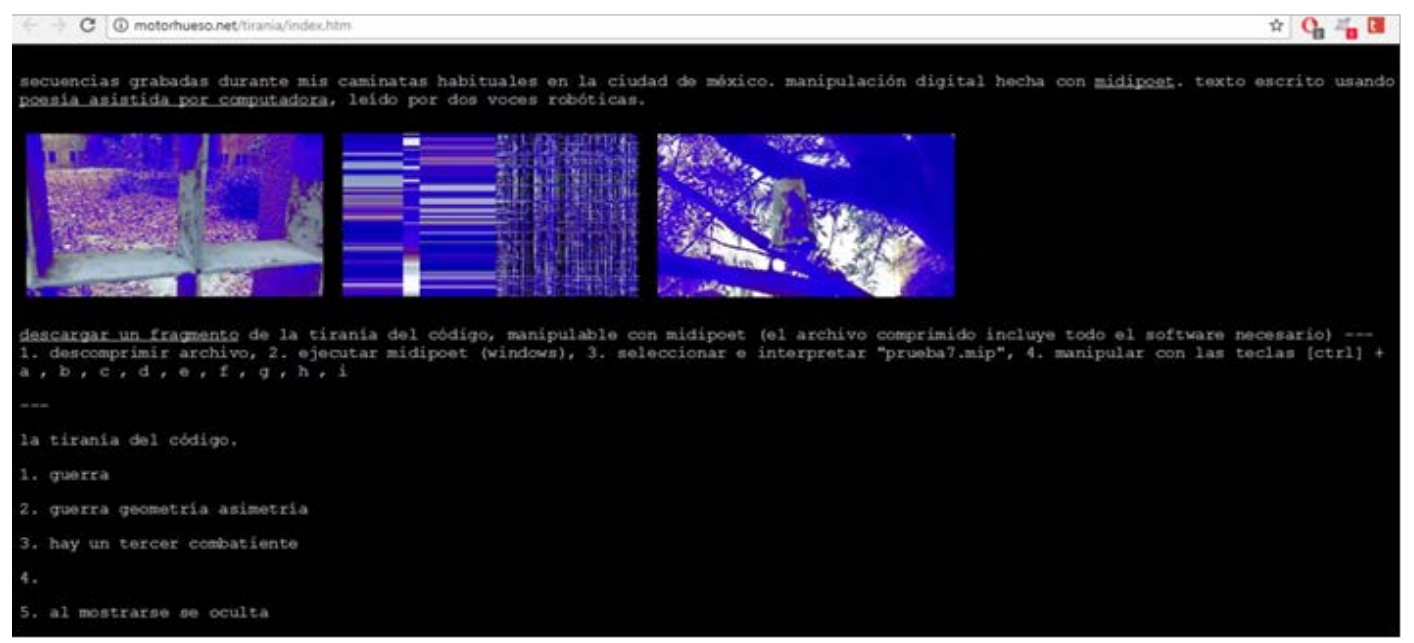

Esta politización de la práctica de la poesía digital se ha hecho muy evidente en las obras que Tisselli produjo en ańos recientes, tanto a partir de su residencia temporaria en México como en la prosecución de su proyecto en Tanzania. Como momento que de algún modo marca esta transición, el autor publicó en 20II un texto/declaración en el que informaba que dejaría de crear por un tiempo literatura digital, motivado por la falta de conciencia que en general se tiene en la vida cotidiana tecno-globalizada —incluida la de los propios artistas que hacen arte digital—, en relación con las geopolíticas de las materialidades que intervienen en los dispositivos electrónicos -materias primas contaminantes y extraídas en lugares periféricos y precarizados del planeta en condiciones de sojuzgamiento- - Y también, dejaría de crearla para cuestionar un tipo de literatura digital concebida solamente con el fin de explorar nuevos formatos y medios. Algo que el propio Tisselli estaba quizá reconociendo implícitamente como — al menos — parte de su obra anterior. En ese texto, hacía un llamado a

una verdadera investigación en literatura electrónica intersectorial y trans-disciplinaria, que involucre también una comprensión profunda de sus efectos ambientales y económicos. Que no ignore los contextos sociales y culturales que están siendo destruidos en favor de nuestra tecnología. Pienso específicamente en África y muchos otros lugares alrededor del mundo donde la tierra es apropiada y explotada y donde las sociedades están condenadas a sufrirlo. ${ }^{11}$ 
Esta declaración tuvo como punto de partida la confrontación con las condiciones materiales de existencia en África, a partir de un viaje a Tanzania para producir, en un trabajo colaborativo con granjeros locales de subsistencia, una base de conocimiento online que diera cuenta de sus prácticas, necesidades e innovaciones, y que sería una plataforma de intercambio entre ese conocimiento local e investigadores dedicados a temas de agricultura. La decisión de frenar la creación de literatura digital puede leerse en realidad como una decisión de virar la dirección de esa creación hacia la práctica de escrituras colectivas en comunidades extendidas, como forma de experimentar lo digital en el matiz y la contradicción.

Así, teniendo en cuenta contextos de desarrollo geopolítico desigual, una línea significativa de literatura digital latinoamericana es sensible a las interdependencias sociales, políticas y económicas que conlleva el uso de nuevas tecnologías, aun cuando los artistas —incluyendo a Tisselli- las asuman como potencias creativas. Habría de este modo una tensión entre un adentro y un afuera de los paisajes tecnológicos contemporáneos globalizados y su dominio digital. A ello se agrega la problematización que se da en algunas zonas de la literatura digital latinoamericana de realidades interculturales que implican desasignarse de modelos artísticos hegemónicos occidentalizados. En este sentido, destacan esas producciones actuales de Tisselli que pueden recorrerse en su proyecto ojoVoz en las que, como comenta él mismo (2015), interviene no tanto en calidad de artista sino de infiltrado en equipos transdisciplinarios de biólogos y agrónomos que trabajan en comunidades en general de campesinos. Proyectos

como Sauti ya wakulima en Tanzania, o Los ojos de la milpa en la Sierra Mixe de Oaxaca, son intentos por insertar el presente de las comunidades campesinas (que muchos modernos llaman arrogantemente pasado) en nuestro propio presente urbano (...) me infiltro en las comunidades con las que trabajo y convivo. Busco instigar así la creación de memorias comunitarias digitales.

Me detengo por último en una de las piezas que en el sitio web del artista aparecen bajo el rótulo de politica algoritmica. The 27th/El 27 es una obra de activismo artístico algorítmico o de poesía conceptual tecnológica que interviene en el necrocapitalismo contemporáneo — concepto que Tisselli reformula a partir del de necropolítica de Achille Mbembe- a partir de una traducción al inglés en forma aleatoria de fragmentos del artículo 27 de la Constitución mexicana, luego de su reforma neoliberal de 2013. Esta reforma entiende sobre la posesión de recursos naturales nacionales de modo de que puedan ser derivados a manos privadas.

El algoritmo de traducción al inglés que interviene es disparado por el mercado. En el ángulo izquierdo superior de la obra se lee el siguiente texto explicativo: "Cada vez que el Índice Compuesto de la Bolsa de Valores de Nueva York (Símbolo: ${ }^{\wedge} \mathrm{NYA}$ ) cierre con una variación porcentual positiva, un fragmento del artículo 27 de la Constitución Política de los Estados Unidos Mexicanos será traducido automáticamente al inglés» (Fig. 4 The 27th/El 27, mercado en baja; Fig. 5 The 27th/El 27, mercado en alza). 


\section{The 27th. El 27.}

[EN] Each time the Nesw York Stock Exchange Composite Index (Symbol: "NYA) closes with a positive percent variation, a fragment of the

[ES] Cada vez que el fndice Compuesto de la Bolsa de Valores de Nueva York (Simbolo: NYA) cierre con una variación porcentual positiva, un fragmento del articulo 27 de ingles. [más]

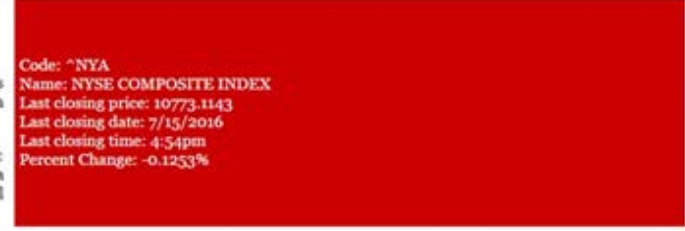

ARTICUL 27 LAND PROPERTY AND FALUNG WATERS WTTHIN THE BOUNDARIES OF THE NATIONAL TERRTTORY, ORIGNALLY CORRESPONDS TO THE NATION, LA CUAL AA TENIDO Y TIENE EL. DERECHO DE TRANSMITIR EL. DOMINTO DE EULAS A LOS PARTICILARES, CONSTTTUYENDO LA PROPIEDAD PRIVADA

LAS EXPROPLACIONES SOLO PODRAN HACERSE POR CAUSA DE UTHIDAD PUBLICA Y MEDLANTE INDEMNIZACION

HE NATION WIL HAVE AT AL TIMES THE RIGHT TO IMPOSE OX PRIVATE PROPERTY MODALTIES THAT DICTATES THE INTEREST PITLL, ASI COMO EL. DE REGULAR, QN BENEFICIO SOCLAL, EL. APROVECHLMMENTO DE LOS ELEMENTOS NATURALS SU SCEPTIBLES DE, APROPLACION, NN ORDER TO MLAKE AN EQUTTABLE DISTRIBUTION O WEALTH PUELIC, CUIDAR DE SU CONSERVACTON, LOGRAR EL DESARROLLO EQUULIRADO DEL PAIS Y EL. MEJORAMIIENTO DE LIS CONDICIONES DE VIDA DE LU POBLACION RURAL Y UREANA EN CONSECUENCLA, WERE RENDERED MEASTRES NECESSARY TO ORDER HUALAN SETTLEMENTS AND ESTABLISH APPROPRLATE PROVISIONS, USOS, RESERVATIONS AND DESTINATIONS OF LANDS, AGUAS Y BOSQUES, A EFECTO DE EJECUTAR OBRAS PTIBLCAS Y DE PLANEAR Y REGULAR LA

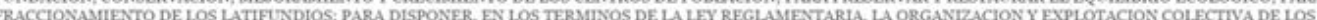

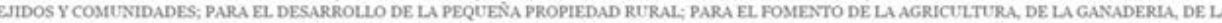
EIVICULTURA Y DE LAS DEMAS ACTIVIDADES ECONOMICAS EN EL, MEDIO RURAL, Y PARA EVITAR LA DESTRUCCION DE LOS ELEMENTOS NATURAIES Y LOS DAÑOS QUE LA PROPIEDAD PUEDASCFRIR EN PERJUICIO DE LA SOCIEDAD.

CORRESPONDE A LA NACION EL DOMINIO DIRECTO DE TODOS LOS RECURSOS NATURALES DE LA PLATAFORMA CONTINEATAL Y LOS ZOCALOS SUBMLARINOS DE LAS ISLAS; DE TODOS LOS MINERALES O SESTANCLAS QUE EN VETAS, MANTO MASAS O YACIMIENTOS, CONSTITUYAN DEPOSTTOS CIYA NATURALEZA SEA DISTINTA DE LOS

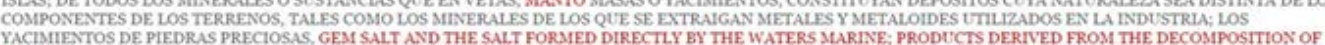

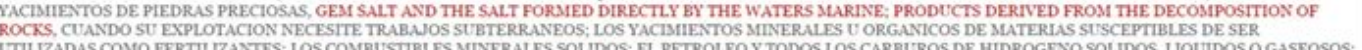

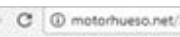

\section{The 27th. El 27.}

[EN] Each time the New York Stock Exchange Composite Index (Symbol: ^NYA) closes with a positive percent variation, a fragment of

[ES] Cada vez que el findice Compuesto de la Bolsa de Valores de Nueva York (Simbolo: NYA) cierre con una variación porcentual positiva, un fragmento del articulo 27 de 1 Constitución pols.
ingles. [mas]

\section{ARTICLE 27. LAND PROPERTY AND FALIING WATERS WTTHIN THE BOUNDARIES OF THE NATIONAL. TERRITORY, ORIGINALLY CORRESPONDS TO THE NATION, WHICH HUS HAD AND HAVE THE RIGHT TO TRLNSMIT THE DOMANN OF THESE INDIVIDUAIS, CONSTITUTING PRRVATE PROPERTY, \\ EXPROPRLATIONS MLAY ONLY BE BECAUSE OF USEFULNESS PUBLIC AND THROUGH CONPENSATION \\ THE NATION WTL HAVE AT ALL TIMES THE RIGHT TO DMPOSE ON PRIVATE PROPERTY MODALITIES THAT DICTATES THE INTEREST PUBLIC, AS WELL AS THE REGULAR, SOCLAL BENEFIT, EL APROVECHAMIENTO DE LOS ELEMENTOS NATURALS SUSCEPTIBLES DE APROPLACION, IN ORDER TO MLKE AN EQUTTABLE DISTRIBUTION O

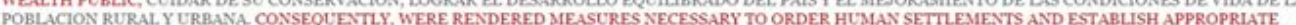 PROVISIONS, USOS, RESERVATIONS AND DESTINATIONS OF LANDS, WATER AND FORESTS, TN ORDER TO EXECUTE WORKS TO PUBLIC AND TO PLANAND REGILUTE THE FOUNDATION, CONSERVACION, IMPROVEMENT AND GROWTH OF POPILATION CENTRES; TO PRESERVE AND RESTORE THE ECOLOGICAL BALANCE; FOR THE FRACTIONATION OF THE ESTATES. PARA DISPONER, EN LOS TERMMNOS DE LA LEY REGLAMENTARIA, THE ORGANIZATION AND COLLECTIVE EXPLOITATION OF THE

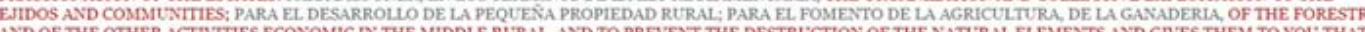 CORRESPONDSTOTHE \\ TESOURCES NATURAL OF IT PLATFORM CONTINENTAL. AND THE SOCKETS SLBMARINE OF THE ISLANDS; DE TODOS LOS MINERALES O SUSTANCLAS QUE EN VETAS, MANTO MASASO YACIMIENTOS, CONSTITUTE DEPOSITS WHOSE NATURE IS DIFFERENT FROM THE COMPONENTS OF THEM LAND, SUCH AS MINERAIS THAT ARE EXTRACTED METALS AND NON-AETALS USED IN INDUSTRY; LOS YACISIENTOS DE PIEDRAS PRECA NECESIIE TRABAJOS SUETERRANEOS; LOS YACIMIIENTOS MINERALES U ORGANICOS DE MATERLAS SUSCEPTIBLES DE SER UTHLZADAS COMO FERTILIZANTES; SOLID}

La pieza fue puesta en línea dos veces: la primera vez, el I de enero de 20I4, a veinte años de la firma del Tratado de Libre Comercio de América del Norte (TLCAN), más conocido por su sigla en inglés, NAFTA. La segunda vez, en febrero de 2016 una vez que el texto de la Constitución había sido sustituido casi por completo por su traducción automática al inglés. A su vez, el mercado es asociado aquí con intereses económico-políticos como los que en México se ocultan, por ejemplo, detrás de la desaparición de los 43 estudiantes de Ayotzinapa, mencionados por Tisselli (20I5a) en el ensayo que acompaña y — se diría, forma parte de - la obra: «el verdadero poder se traslada directamente a las manos del capital, que es ahora quien ordena quién vive y quién muere».

Visualmente, además, la intrusión del texto en inglés, en letras rojas, en reemplazo de las grises originales del texto en español, se puede asociar fácilmente con esa línea de sangre del necrocapitalismo. Aunque por otro lado, los colores de la pieza son básicamente los de la bandera mexicana. Sobre un fondo de pantalla blanco, el texto se reparte en dos grandes zonas: la inferior muestra el artículo 27 de la constitución mexicana; la superior está subdivida en dos paneles, el de la izquierda incluye el título y el breve texto explicativo ya mencionado en letras
Fig. 4 Eugenio

Tisselli. The 27th/El 27, mercado en baja, captura de pantalla julio de 2016
Fig. 5 Eugenio

Tisselli. The 27th/El

27 , mercado en alza, captura de pantalla junio de 2017 
negras; el de la derecha, un rectángulo que muestra en tiempo real la información de cierre del mercado de valores cada día sobre un fondo rojo — si el mercado cerró en baja — o verde — si cerró en alza—. Los colores de la bandera de México aparecen así, inversamente, cada vez que el texto de su constitución es invadido.

Así, la obra puede leerse como poesía digital conceptual que discute los modos en que tanto el capital como los lenguajes naturales y artificiales intervienen en la cultura globalizada contemporánea. El español transmuta en inglés por medio de un algoritmo que capta información del mercado financiero global. Y esa información dispara una mixtura de lenguajes natural y artificial. Pero como señala Tisselli (20I5a), no se trata de proponer una inversión que nos liberaría de la política algorítmica del necrocapitalismo sino por el contrario, de profundizar aún más la dirección habitual que adopta esa política: cuando el mercado está en alza, la calidad del lenguaje natural decrece ya que el español es reemplazado por un inglés macarrónico «incorrecto pero eficaz» (2015a). Ninguna lengua gana: ni el español que va desapareciendo del texto ni el inglés que lo reemplaza, convertido en una lengua robótica. Hay algo del orden de la memoria de la lengua, y sus territorios, que se diluye en la transformación del texto y nos interpela desde esa ausencia.

Lo que me permite pasar, por último, a algunas consideraciones en torno de una zona de las obras de Gabriela Golder - que tanto la artista como quienes escriben sobre su obra rotulan como net.art, pero que sin duda puede adscribirse a la literatura digital—, donde también memoria, lengua y localización/deslocalización se hacen presentes en sentido fuerte. ${ }^{12}$

Así por ejemplo Postales (2000), una obra hipermedial online que según la presentación inicial que hace la autora «habla de una poética de lo extranjero», y que nos enfrenta a una navegación en la que el desplazamiento es hilo conductor: desplazamiento de idiomas - la obra presenta, aleatoriamente para quien lee, textos tanto en español como en francés, incluso textos que al pasar por encima el cursor mudan al otro idioma-; de géneros discursivos — diario íntimo y de viaje, poesía, prosa poética — y de lenguajes — visual, sonoro, imagen movimiento, verbal- (Fig. 6 Postales-postal-3; Fig. 7 Postales-postal-26).

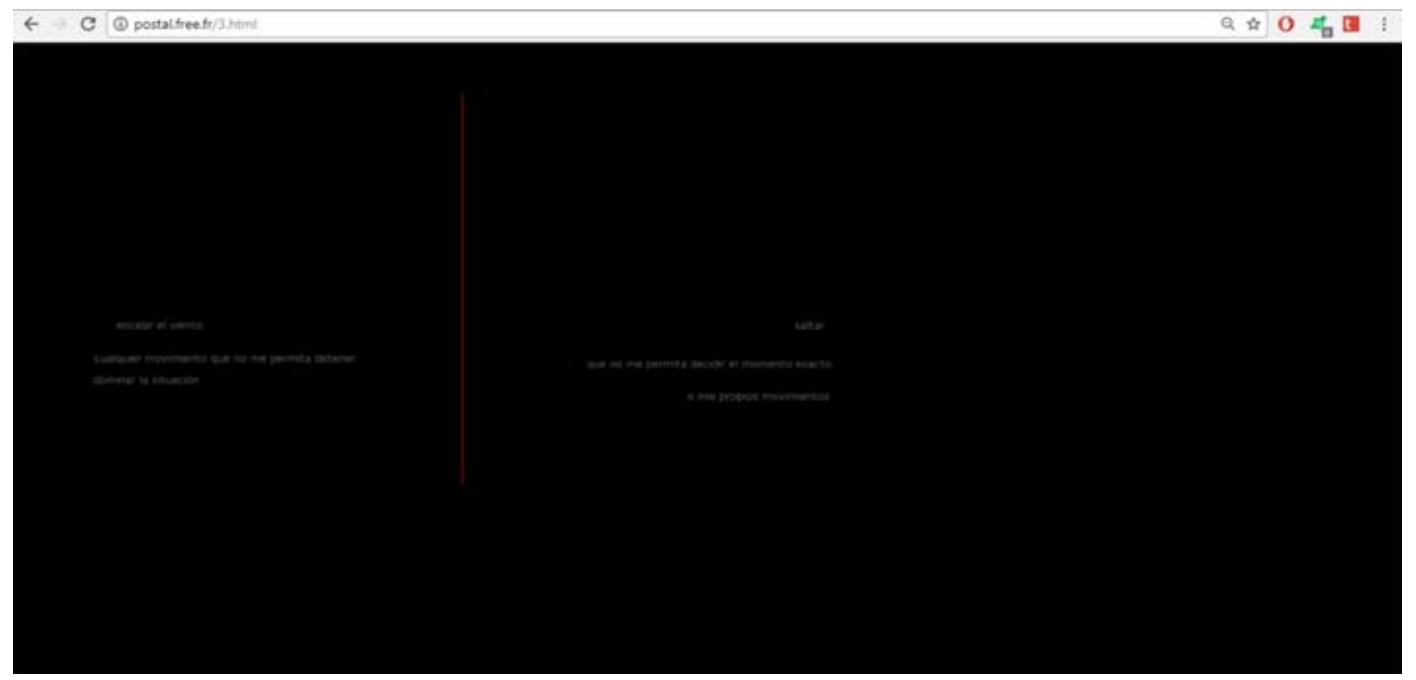




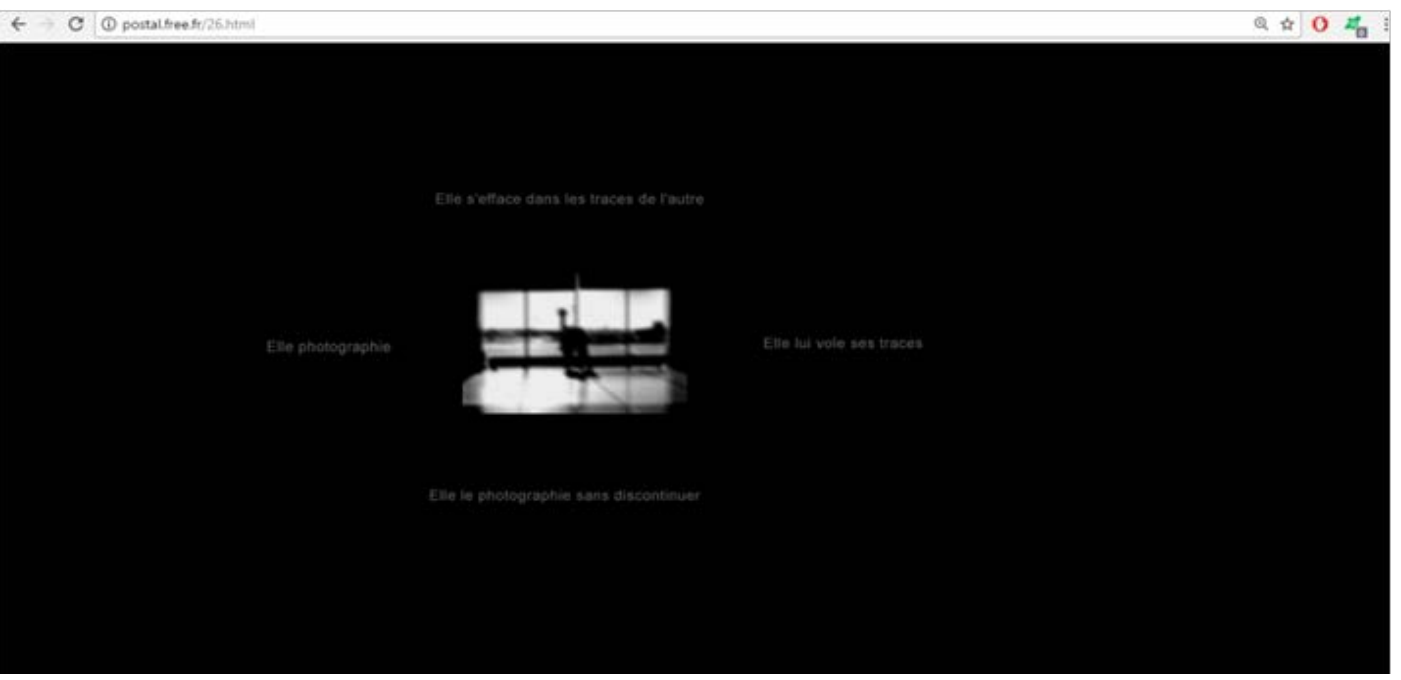

Fig. 7 Gabriela Gol-

der. Postales, 2000, postal 26, captura de pantalla junio de 2017

Integro esta obra a lo que llamo el «corpus migrante de la literatura digital latinoamericana», es decir, un grupo de obras en cantidad considerable que exhibe, discute, disemina desplazamientos entre lenguas, desde una posicionalidad latinoamericana, muchas veces como comentario en relación con los procesos de migración que impulsa la misma globalización. Los artistas mismos son con frecuencia migrantes. Si bien los desplazamientos de personas adquieren en contextos de globalización diversos matices — más o menos deseados, forzados o dramáticos según los casos-, lo que hace que en general no pueda atribuirse al desplazamiento de los artistas el mismo tenor que el de los desplazados de la globalización, o al menos no el mismo dramatismo, la experiencia migrante deja de todos modos huella en las obras. Sea el desplazamiento motivado por razones personales, económicas o profesionales, se deja leer en las obras a partir de una serie de procedimientos que muchas veces asumen la extrañeza que produce la diferencia lingüística.

Postales se compone de 220 pantallas — una «postal» en cada caso-, que aparecen de acuerdo a recorridos interactivos que, sin embargo, quien lee/interactúa no puede predeterminar; aparecen por tanto en la lectura con cierto grado de aleatoriedad, aunque no sean completamente aleatorios. Así, a veces, algunos recorridos parecen conducir siempre a un callejón sin salida, es decir, a una pantalla desde la cual no se puede seguir adelante; a veces se producen recorridos de algún modo circulares; a veces aparece una ventana emergente — da instrucciones de navegación, pero otras veces — cuando más se lo espera- estas instrucciones no aparecen. En este sentido, la obra juega con cierta opacidad ya que los hipervínculos que habilitan la interacción no se muestran sino que quedan ocultos en muchas de las postales en zonas no necesariamente obvias, por lo que hay que ir en su búsqueda, con insistencia, para poder continuar. Se trata de un procedimiento que exhibe el «revés de la trama» de la cultura digital, al desacostumbrar la vinculación que tenemos con la navegación online que, en general, tiende a la amigabilidad y la eficiencia como modo de retener al internauta. La irrupción de los pop ups, además, muestra de forma evidente la materialidad de la interfaz como modo de desnaturalizar los recorridos y la referencialidad de 
la obra, ya que no solo estos pop ups pueden contener instrucciones de navegación sino también notificaciones extrañadas como las ventanas emergentes de notificación que señalan en boca del programa ya sea «je ne parle pas français», ya sea «tu ne parles pas espagnol». En la interacción habitual con computadoras, este tipo de ventanas emergentes acostumbran a una suerte de diálogo con el programa que nos advierte respecto de alguna impropiedad por parte de nuestra interacción. En este caso, el efecto de extrańamiento se refuerza, por supuesto, porque las ventanas emergentes no suelen decirnos que no hablan francés o que nosotros no hablamos español. Cierto es que esas frases podrían ser enunciadas por el propio "yo» de la obra, ese sujeto del enunciado que se reconoce en una voz que habla constantemente del desplazamiento, el desfasaje de un sujeto en tránsito, la imposibilidad de ser completamente en una lengua otra o el temor al olvido. Pero desde el lado de la lectura de Postales, esas ventanas emergentes que, además, son difíciles de cerrar — se abren una y otra vez y, nuevamente, hay que insistir para cerrarlas - no le hablan al «vos» interlocutor interno del «yo» que enuncia los textos, sino a los lectores fuera de la obra, destinatarios directos de la interfaz (Fig. 8 Postales-pop up.I; Fig. 9 Postales-pop up.2).

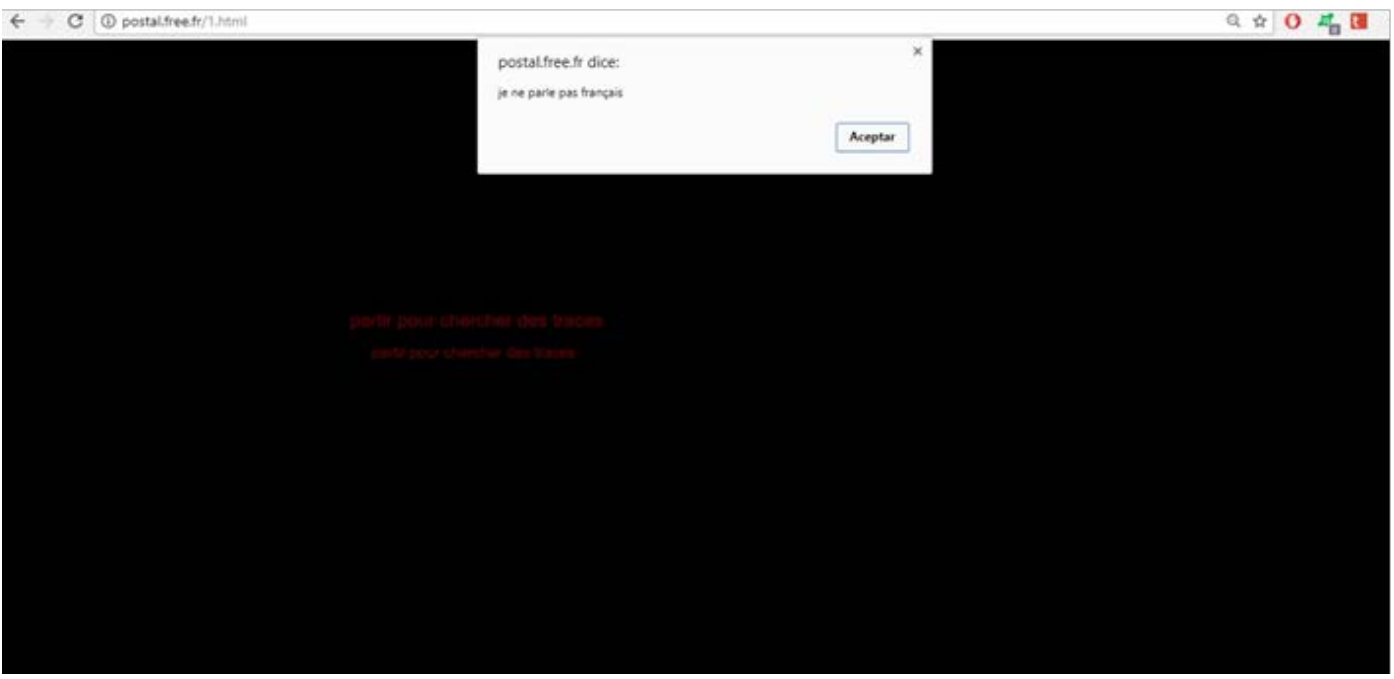

Fig. 8 Gabriela Golder. Postales, 2000, pop up.I, captura de pantalla junio de 2017

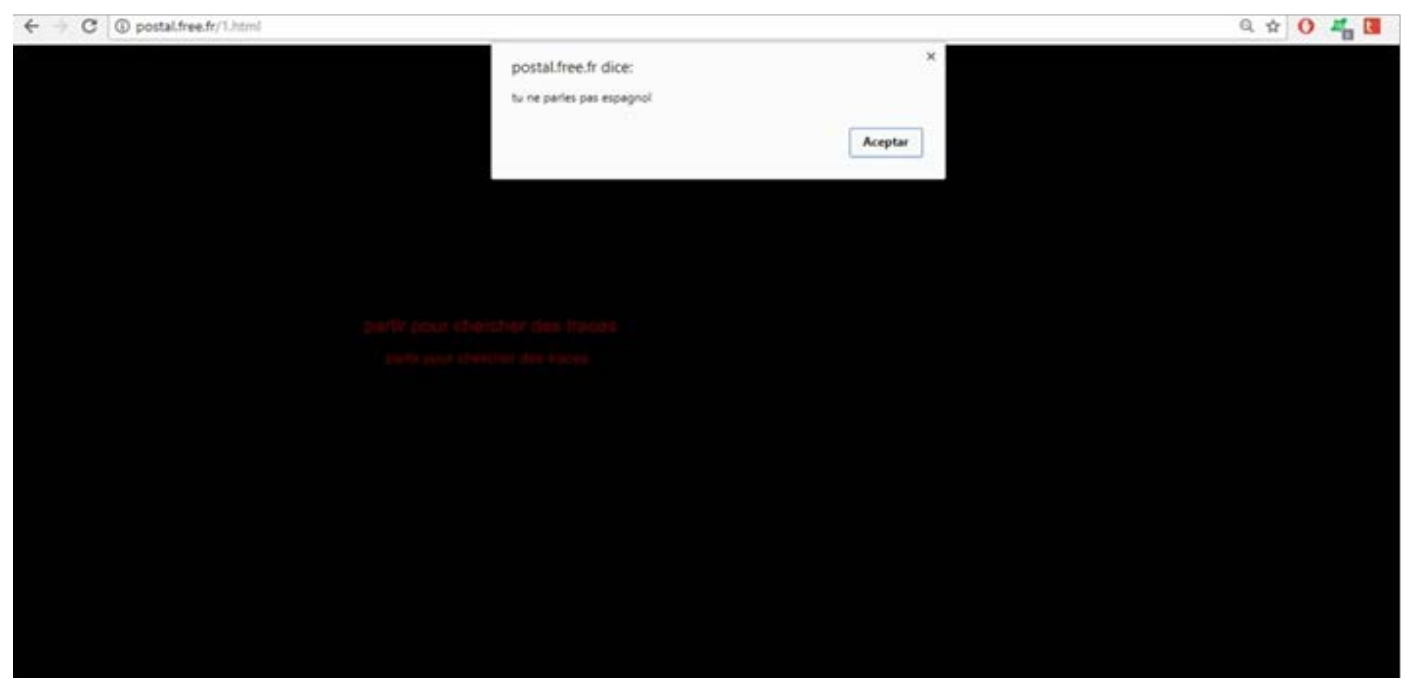

Fig. 9 Gabriela Golder. Postales, 2000, pop up.2, captura de pantalla junio de 2017 
La estética de Postales es a la vez minimalista e intimista. Los colores son muy pocos: pantalla negra, letras y líneas blancas, grises o rojas, imágenes en blanco y negro o con colores apagados. Viejas fotos de familia, paisajes urbanos, cuerpos desnudos que vinculan una historia de desarraigo con una historia de amor, se van entramando en los recorridos. Las imágenes o los textos pueden quedar fijos, suspendidos en la pantalla, pero también en ocasiones tienen movimiento, se desplazan ya sea en sentido horizontal o vertical. El conjunto ofrece un relato de viaje fragmentario en tono de prosa poética algo opresiva o melancólica que, aunque parece centrada solamente en la historia de intimidad de un «yo» y un «vos» —también un «je»y un «tu», incluso «moi» y «toi» que en alguna de las postales se intercambian entre sí al pasar el cursor por encima del texto- habla también desde las imágenes y desde el dispositivo de la historia que excede lo íntimo y conecta el viaje, como queda ya dicho, con el desarraigo (Fig. Io, Postales-postal 50; Fig. II. Postales-postal IO2a; Fig. I2 Postales-postal I23).

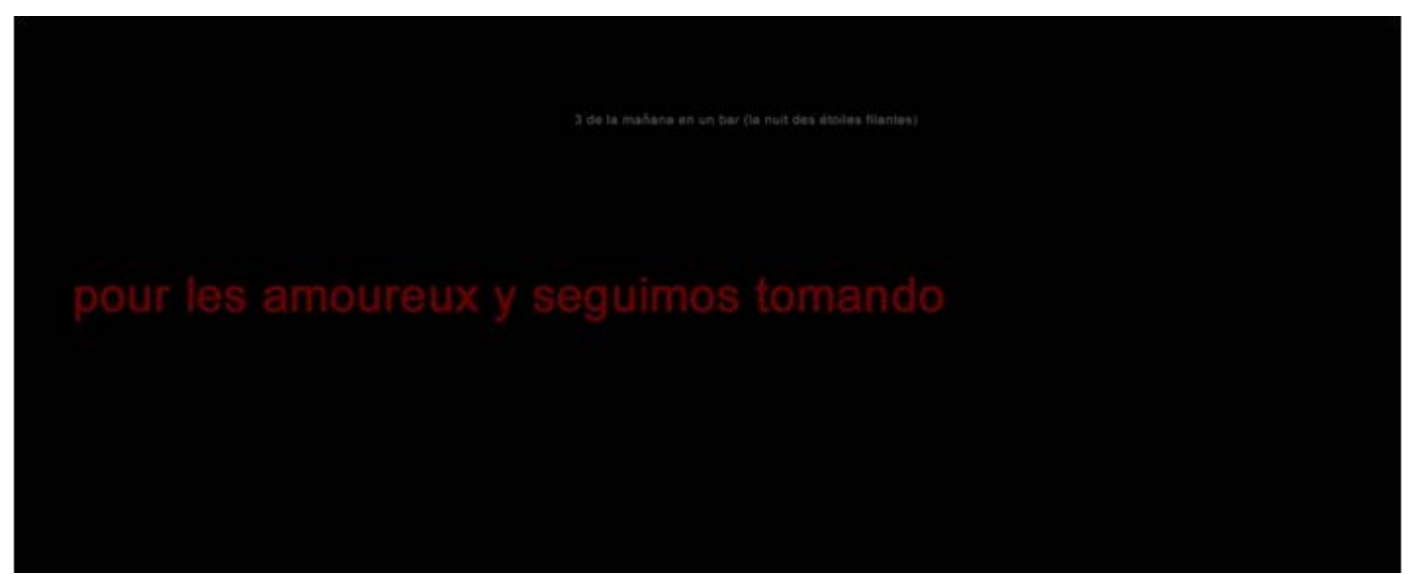

Fig. Io Gabriela Golder. Postales, 2000, postal 50, captura de pantalla junio de 2017

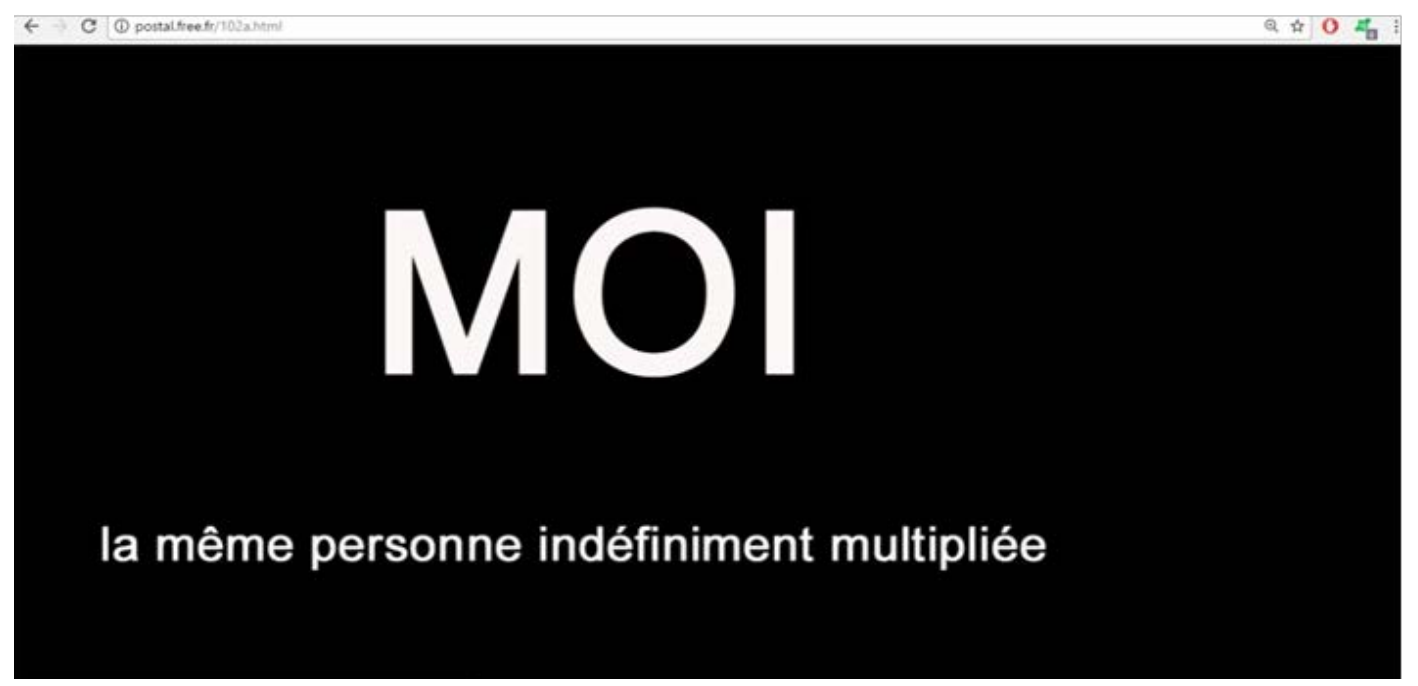

Fig. II Gabriela Golder. Postales, 2000, postal IOza, captura de pantalla junio de 2017 


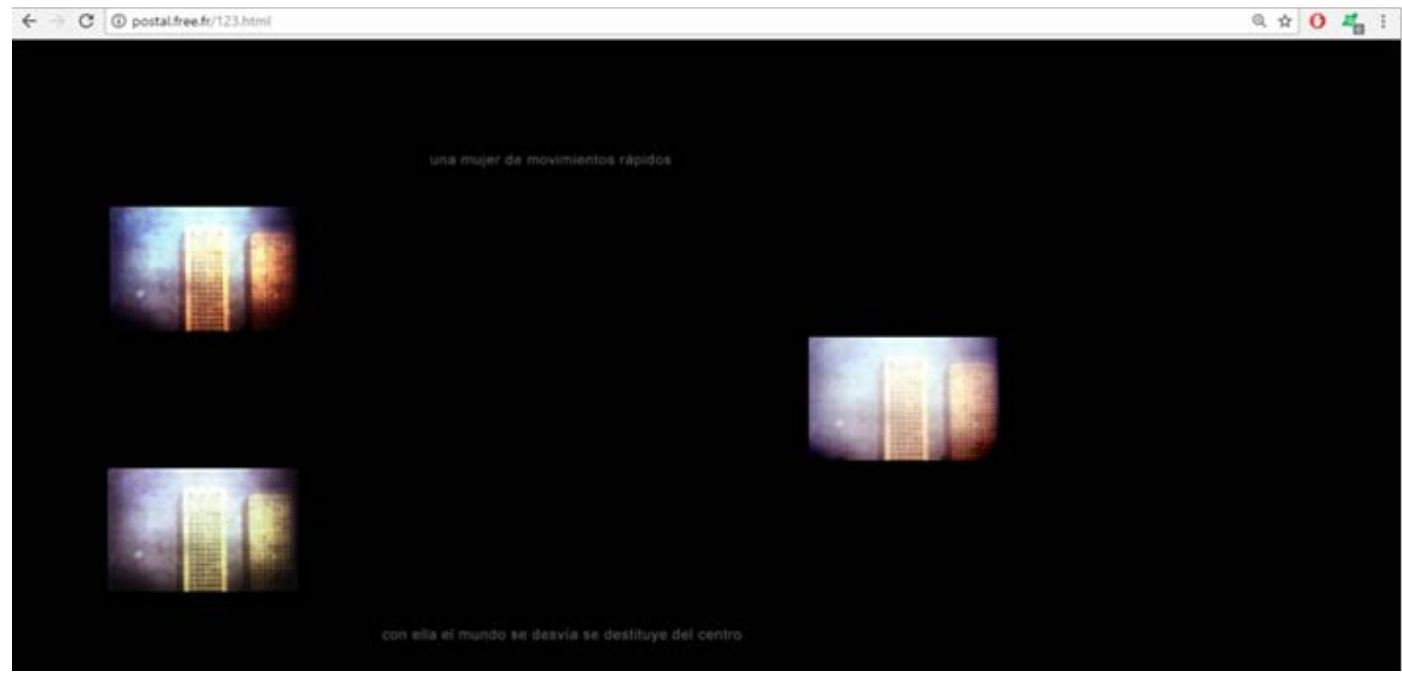

Fig. I2 Gabriela Gol-

der. Postales, 2000, postal I23, captura de pantalla junio de 2017

Otra obra de Golder que convierte el net.art en literatura expandida digital es Rescate (2009), una obra construida con palabras extraídas, rescatadas, de libros censurados durante la última dictadura militar en la Argentina. Las palabras van apareciendo aleatoriamente en la pantalla y nos interpelan a que las atrapemos pasando el cursor. Sobre fondo blanco, estas palabras sueltas en tipografía negra, de trazo regular, se mueven, se agrandan, como viniendo desde el fondo a primer plano y van armando breves poemas visuales y sonoros — solo por contigüidad- que se forman y deforman, se hacen y deshacen. A poco de comenzar a interactuar nos damos cuenta de que es preciso estar alertas a la aparición de las palabras que más nos convocan, de modo de que al atraparlas vengan a primer plano y se modifique su sonoridad. Mientras las palabras que aparecen en pantalla son dichas por una voz que, al igual que la tipografía, es regular, cuando son «atrapadas» por el cursor, en cambio, se dicen en un susurro. Como en muchas otras obras de literatura digital cada texto es muchos textos, tantos como perdure nuestra actividad lectora/interactora. «Porque se dicen, las palabras son. Porque se dicen, escapan al olvido", sostiene el texto explicativo de la obra - texto curatorial de la propia autora, algo frecuente en las obras de arte digital en general (Fig. I3 Rescate, I; Figura I4 Rescate, 2).

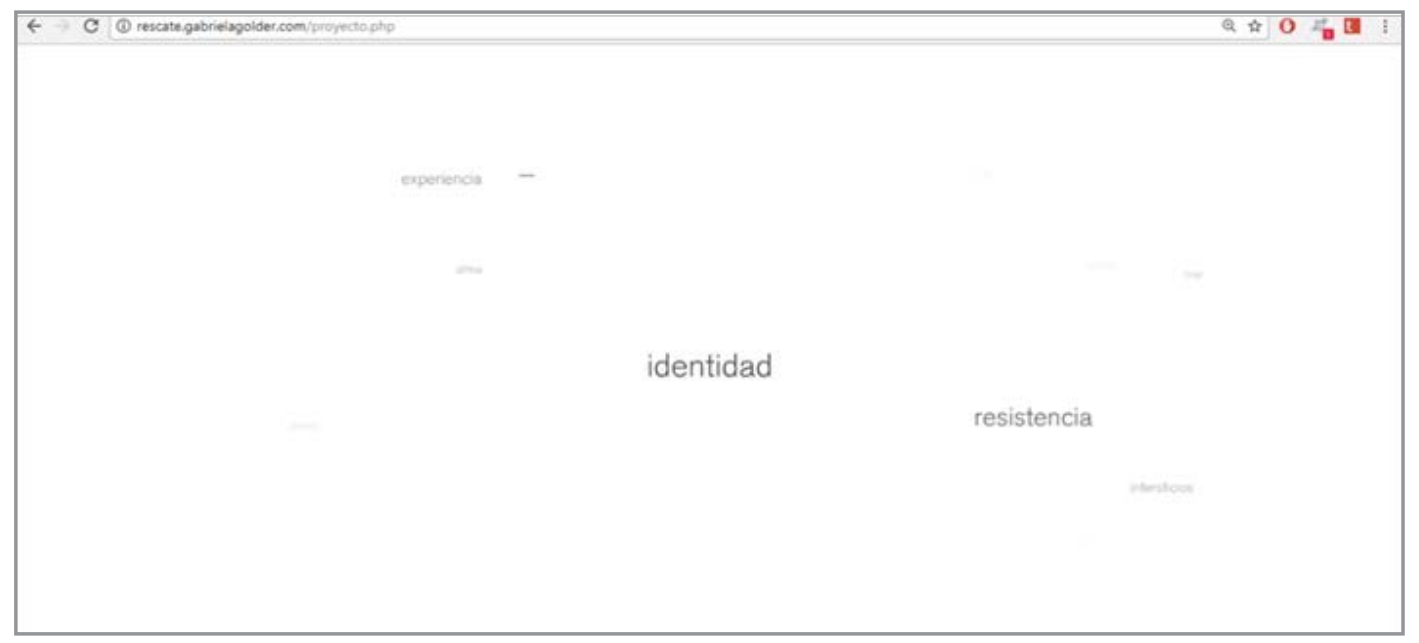

Fig. 13 Gabriela Golder. Rescate, 2009, I, captura de pantalla junio de 2017 


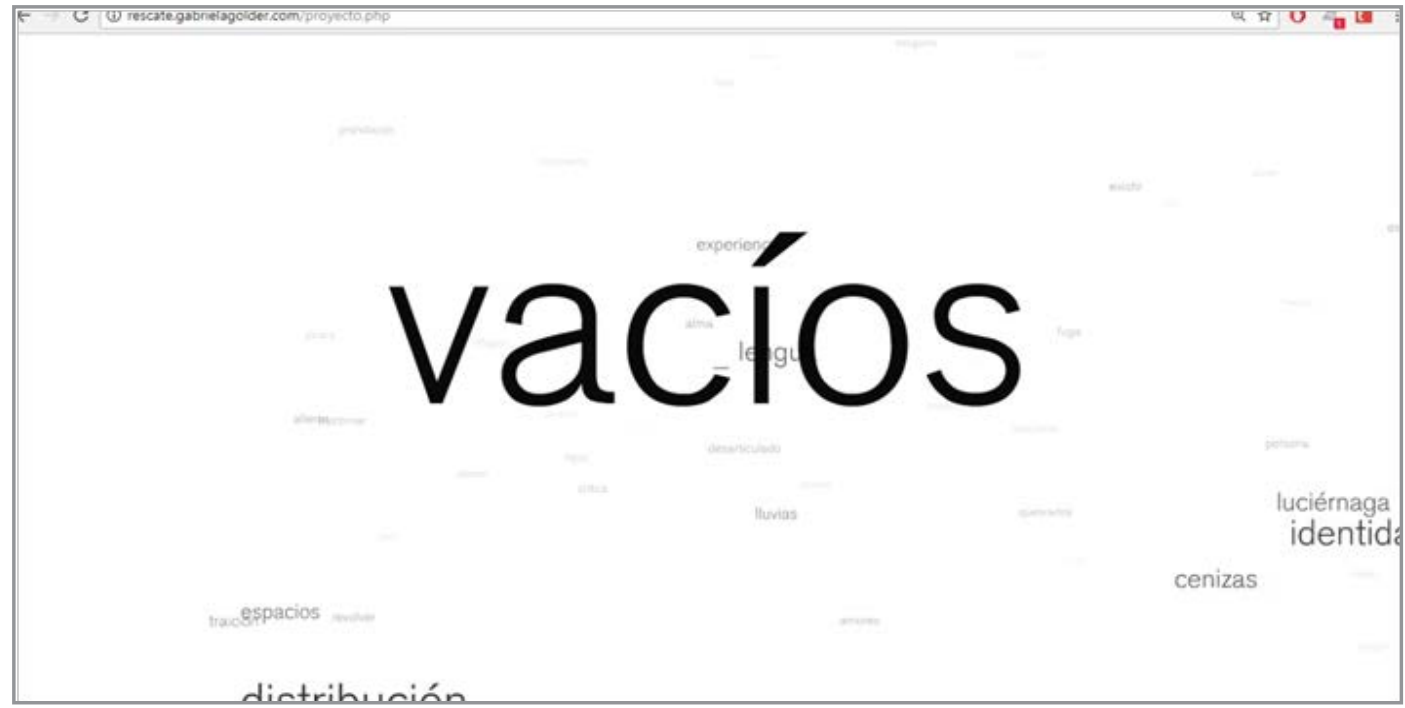

Fig. I4 Gabriela

Golder. Rescate,

2009, 2, captura de

pantalla junio de

2017

¿Cómo hacen sentido las múltiples variaciones y combinaciones de Rescate? En primer lugar, el paratexto de la obra — como el texto de presentación titulado "Sobre el proyecto»- enmarca y da el sentido general, crea una ambientación marco de la que nuestra actividad lectora irá seleccionando regiones para hacer más visibles y audibles unas y dejar pasar otras. Pero los poemas que podríamos así ir creando pasan, no se fijan. Vienen a primer plano en forma momentánea y luego se dispersan sin que las mismas opciones de palabras se nos vuelvan a ofrecer en el mismo orden. Se construyen así poemas efímeros que quedarán resonando sólo en quien haya interactuado en ese preciso momento y lugar. La obra quedará como caja de resonancia en potencia.

En cuanto a las palabras específicas que se nos ofrecen en esta obra, no se explicita de qué libros provienen, sólo se explica que podrían haber sido otros libros y otras palabras. Pero son éstas, y con ellas hacemos poemas básicamente nominales. Se observa en efecto que sería ésta una poesía de nombres, nominal, hecha casi en su totalidad de sustantivos, muy pocos adjetivos y muy pocos verbos muchos de ellos en infinitivo, nominalizados. Casi nada más. Rescatadas del olvido, de la ausencia, las palabras se dicen y por ello son. De allí que se nombren a sí mismas y que modulen otra voz al ser rozadas y traídas a presencia. Dar nombre, dar palabra, a falta de cuerpos ausentes, desaparecidos, y de historias acalladas, es lo que la obra convoca. En vez de cuerpos, libros ausentes traídos al presente en palabras dispersas y susurros. Algo que, a falta de esos cuerpos negados violentamente, todavía es preciso. Que pueda hacerse desde una literatura expandida bajo el dominio digital dice mucho y bien de una literatura que, parafraseando la cita de Borges con la que he iniciado este texto, sabe profetizar aquel tiempo en el que habrá enmudecido, encarnizarse con la propia virtud y enamorarse de la propia disolución. 


\section{Notas}

1 Se trata en tal caso de «uma literatura que se expande para o espaço expositivo não mais circunscrita à palavra o à comunicaçáo linguística, mas pluridimensional. Nessa hibridação de literatura e artes visuais, surge uma literatura expandida» (Pato:40). Si bien incluyo en mi acercamiento a la literatura expandida digital obras que se vuelcan hacia el espacio expositivo como parte o todo en, por ejemplo, instalaciones, la literatura digital se ubica también en un fuera de sí respecto del sistema de las artes visuales contemporáneas.

2 Rodrigo Alonso señala que en 1968 Jack Burnham en su libro Más allá de la escultura moderna, consideraba diversas formas de ampliación del campo de la escultura al referirse al arte cinético, las esculturas luminosas o el arte cibernético, entre otros. Y sugiere que esto dio lugar a que se fuera gestando también la noción de cine expandido que sería retomada por Youngblood (Alonso).

${ }^{3}$ En su breve reseña en El País del último libro de Graciela Speranza, Cronografias. Arte y ficciones de un tiempo sin tiempo, Enrique Vila-Matas atribuye esto a Ana Pato, con la aparición en 2012 de su libro Literatura expandida. Arquivo e citação na obra de Dominique Gonzalez-Foerster. Sin embargo, en 2003 Mieke Bal publicó un artículo denominado «Meanwhile: Literature in an expanded field", que retomaba la idea de campo expandido para poner a la literatura en ese contexto -Internet, la globalización y los estudios poscoloniales por ejemplo- aunque en realidad analizaba una novela «no expandida». Tomando en cuenta acepciones más cercanas a las que aquí propongo, en 2008 se realizó en el Ayuntamiento de Barcelona la segunda edición del congreso Neo3, organizado por Eloy Fernández Porta, articulado explícitamente alrededor de la idea de literatura expandida, como se desprende del apartado denominado «Descriptor» en su programa (Neo3). En 2009 Stefano Leoncini publicó el artículo «Expanded literature. Réflexions autour des "mots du cinéma" dans la prose tabucchienne». En el mundo hispanoparlante, el sitio Web Sociedad Lunar. Literatura expandida (http:// sociedadlunar.org/) tiene ya varios ańos, lo mismo que el ciclo Literatura expandida del Museo Universitario del Chopo de la unam en México.
4 Algunos fragmentos de este apartado y del siguiente, en los que desarrollo una definición de la literatura digital así como consideraciones acerca de su historia y sus géneros, presentan reelaboraciones y ampliaciones de lo adelantado en Kozak 20I7b.

5 Espen J. Aarseth en su libro Cybertext. Perspectives on Ergodic Literature desarrolló el concepto de literatura ergódica argumentando que se trata de una literatura que, a diferencia de la del libro impreso, requiere del lector nuevas competencias relativas al trabajo (en griego, ergon) del cuerpo para recorrer el camino (hodos) del texto.

${ }^{6}$ No es mi intención aquí presentar una historia exhaustiva del desarrollo de la literatura digital mundial o glocalizada, conceptos que habría por lo demás que discutir. Los ejemplos que doy son solamente ilustrativos en relación con la argumentación desarrollada.

7 Se habla así, por ejemplo, de poesía animada pero también de poesía Flash, haciendo hincapié en este caso en el software utilizado (el programa Flash, hoy ya bastante anticuado, propiedad de la empresa Adobe). Otro ejemplo: tuitpoesía, poesía en 140 caracteres, a manera de un haiku de la era digital, absorbido por el imperativo de la conexión perpetua, de la aceleración, el comentario y la visibilidad mediática o, en su defecto, dirigido hacia una búsqueda irónica meta-mediática.

8 Desde entonces, y sólo para dar un somero panorama de nombres asociados a la poesía digital —uno de los tipos de literatura digital más extendido en Latinoamérica-, en modalidades que incluyen poesía digital visual, sonora, animada, hipermedial y/o generativa, como parte o todo de sus prácticas artísticas, vale mencionar a los siguientes artistas. En Argentina: Ana María Uribe, Belén Gache, Charly Gradin, Fabio Doctorovich, Gabriela Golder, Gustavo Romano, Héctor Piccoli, Iván Marino, Ladislao Pablo Györi, Mariela Yeregui y Milton Läufer; en Brasil: Alckmar Luiz dos Santos, Andre Vallias, Álvaro Andrade García, Chico Marinho, Eduardo Kac, Giselle Beiguelman, Lucio Agra, Wilton Azevedo; en Chile: Carlos Cociña, Martín Gubbins, Orquesta de Poetas; en México: Benjamín R. Moreno, Eugenio Tisselli, Karen Villeda; en Perú: Enrique Beó, José Aburto, Luis Alvarado. 
9 Los primeros generadores automáticos de texto, siendo de los ańos cincuenta y sesenta, no contaban con pantallas. Las obras generadas solo podían leerse impresas en papel.

10 Agamben vincula su noción de experiencia, como infancia del hombre, con la del experimentum linguae que lee en la literatura moderna por excelencia, experiencia del decir el lenguaje, que le permite además vincular experiencia, lenguaje y comunidad. Para llegar a eso se sostiene de la aproximación a Blanchot que realiza Foucault en «El pensamiento del afuera», quien da una imagen de la literatura moderna como aquella que hace de la experiencia del lenguaje su objeto. Un lenguaje que sin embargo no es el lenguaje de tal o cual autor, el lenguaje de tal o cual grupo, sino el hecho de la existencia misma del lenguaje. Con todo lo lejanas que las literaturas expandidas puedan estar de la literatura moderna, me interesan aquellas en la que podemos seguir diciendo, junto a Agamben (22I), que «El contenido del experimentum es sólo que hay lenguaje y que nosotros no podemos representarlo, según el modelo que ha dominado nuestra cultura, como una lengua, un estado o un patrimonio de nombres y de reglas que cada pueblo transmite de generación en generación; más bien sería la inlatencia imposible de presuponer que los hombres desde siempre habitan y dentro de la cual, hablando, respiran y se mueven».

${ }^{11}$ Mi traducción. Si bien Tisselli es mexicano el texto fue redactado en inglés: «So I call for a truly trans-disciplinary, cross-sector research on electronic literature: one that also involves a profound understanding of its environmental and economic effects. One that doesn't ignore the social and cultural contexts which are being effectively destroyed for the sake of our technology. I am thinking specifically about Africa, and many other places around the world in which land is being grabbed and exploited, and where societies are being condemned to suffer».

12 Si bien en su texto de presentación de la obra en el Museo de Arte Moderno de Buenos Aires, María Victoria Simón señala desde un comienzos que tanto en Postales como en Rescate, dos obras de net.art, Gabriela Golder se dirige de manera notable hacia la palabra, no relaciona esto con la literatura digital.

\section{Bibliografía}

agamben, giorgio (2007). "Experimentum linguae». Infancia e historia. Destrucción de la experiencia y origen de la historia. Buenos Aires: Adriana Hidalgo, 213-222.

antonio, Jorge luiz (2008a). Poesia eletrônica. Negociaçóes com os procesos digitais. Belo

Horizonte: Veredas \& Cenarios.

(2008b). «Trayectoria de la Poesía Electrónica en Brasil: Una breve historia».

Escaner Cultural. Revista virtual de arte contemporáneo y nuevas tendencias I03. Web.

ALONSO, RODRIGO (2005). «El espacio expandido». Revista art.es, 6/7, 92-97. Web.

aarseth, espen J. (1997). Cybertext. Perspectives on Ergodic Literature. Baltimore: The John

Hopkins University Press.

BAJTIN, Mijail (1936). «El problema de los géneros discursivos». Estética de la creación verbal,

México: Siglo XXI, 1982, 248-293.

BAJTIN, MIJAIL y PÁVEL MEDVÉDEV (1928). The Formal Method in Literary Scholarship. Baltimore/

London: The John Hopkins University Press, 1978.

воотZ, philippe (2008). «Une poétique fondée sur l'échec». Passage d'encres 33, II9-I22.

(20I2). «La poesía digital programada: una poesía del dispositivo». Claudia Kozak, compiladora. Poéticas tecnológicas, transdisciplina y sociedad: Actas del Seminario Internacional Ludión-Paragraphe 3I-40. Web. 
BOUCHARDON, SERGE (2008). "Une esthétique de la matérialité», en Alexandra Saemmer y

Monique Maza, directoras. E-formes : écritures visuelles sur support numérique. Saint-Etienne:

Publications de l'Université de Saint-Etienne, I35-I44. Web.

BORGES, JORGE LUIS (1932). «La supersticiosa ética del lector». Discusión (Obras completas. 19231972). Buenos Aires: Emecé, 1985, 202-205.

(1952). «Kafka y sus precursores». Otras inquisiciones (Obras completas. 1923-1972).

Buenos Aires: Emecé, 1985, 710-712.

Borràs CASTANYER, LAURA (Ed.) (2005). Textualidades electrónicas. Nuevos escenarios para la literatura. Barcelona: uoc.

BREA, JOSÉ LUIS (1997). «Algunos pensamientos sueltos sobre arte y técnica». La era postmedia. Acción comunicativa, prácticas (pos)artísticas y dispositivos neomediales. Salamanca: CASA, 2002. Web.

BÜRGER, PETER (1974). Teoría de la vanguardia. Barcelona: Península, I987.

DELeUZe, GILles (1987a). «Leibniz, Io/03/1987, El acontecimiento-Whitehead». Les cours de Gilles Deleuze. Web.

(1987b). «Leibniz, Lógica del acontecimiento». Les cours de Gilles Deleuze. Web.

dubois, philippe y otros (2010a). Extended Cinema. Le cinéma gagne du terrain. Pasian di

Prato, Italia: Campanotto Editore.

(20Iob). Oui, Cést du cinéma. Formes et espaces de l'image en mouvement. Pasian di

Prato: Italia: Campanotto Editore.

funkhouser, Chris t. (2007). Prehistoric Digital Poetry. An Archeology of forms, 1959-1995.

Tuscaloosa, Alabama: The University of Alabama Press.

GACHE, BELÉN (2004). Escrituras nómades. Del libro perdido al hipertexto. Buenos Aires: Limbo.

- (2011). «Transgresiones y márgenes de la literatura expandida». Posgrado virtual

Lectura, escritura y educación. Web.

GOICOECHEA DE JORGE, MARÍA (Ed.) (2013). Alicia a través del espejo. Lecturas literárias em el siglo

XXI. Madrid: Fundación Germán Sánchez Ruipérez.

GOLDSMith, KeNNETH (20II). Escritura no-creativa. Buenos Aires: Caja Negra, 2015. Traducción

de Alan Page, Revisión de Mariana Lerner.

HAYLES, N. KATHERINe (2008). Literatura eletrônica. Novos horizontes para o literário. São Paulo:

UPF. 2009. Traducción de Luciana Lhullier y Ricardo Moura Buchweitz.

- (2010). «How We Read: Close, Hyper, Machine». ADE Bulletin I50, 62-79. Web.

KOSKIMAA, RAINER (2005). "Closereading: hipertextos de ficción». En Laura Borràs Castanyer,

editora. Textualidades electrónicas. Nuevos escenarios para la literatura. Barcelona: voc, I77-I9I.

KRAUSS, ROSALIND (1979). «La escultura en el campo expandido», en Hal Foster, compilador. La posmodernidad. Barcelona: Kairos, 1985, 59-74. Traducción de Jordi Fibla.

KOZAK, CLAUDIA (2OI2). «POESÍA DIGITAL E POLÍTICAS DO ACONTECIMENTO», EN MARÍA CRISTINA

franco ferraz e lia cabral baron, editoras. Potências e práticas do acaso: o acaso na filosofia, na cultura e nas artes ocidentais. Río de Janeiro: Garamond/FAPERJ, I93-2IO.

(2013). «Out of bounds. Searching Deviated Literature in Audiovisual Electronic Environments». ELo Conference. Web.

(2016). «Por una literatura fuera de sí. Iвм de Omar Gancedo». Alejandra Torres y Magdalena Pérez Balbi, compiladoras. Visualidad y dispositivo. Los cruces entre el arte y la técnica desde una perspectiva cultural. Los Polvorines: Ungs, 35-47. 
(20I7a). «Latin American Electronic Literature: When, Where and Why». María

Mencía, editora. \#Women Tech Lit. Morgantown, wv, UsA: West Virginia University Press, $55-72$.

(2017b, agosto). «Esos raros poemas nuevos. Teoría y crítica de la poesía digital». El jardin de los poetas. Revista de teoría y crítica de poesia latinoamericana. Mar del Plata.

(Comp.) (2006). Deslindes. Ensayos sobre la literatura y sus límites en el siglo XX.

Rosario: Beatriz Viterbo.

(Ed.) (20I2). Tecnopoéticas argentinas. Archivo blando de arte y tecnología. Buenos

Aires: Caja Negra.

LA FERLA, JORGE (2OII). "Cine expandido o el cine después del cine». 33 cines 4, 7-2I. Web.

lazzarato, maurizio (2006). Politicas del acontecimiento. Buenos Aires: Tinta Limón.

LEONCINI, STEFANO (2009). "Expanded literature. Réflexions autour des "mots du cinéma” dans

la prose tabucchienne». Cahiers de Narratologie, I6. Web.

Marino, Mark (2OII). «The Perl Primer: The Poetry of Techneculture». ELP-oI. Emerging Language

Practices. Electronic Poetry Center. suny-Buffalo. Web.

MORETti, fRANCO (2000). "Conjeturas on World Literature». New Left Review I, 54-68.

- (2007). Graphs, Maps, Trees: Abstract Models for Literary History. Nueva York:

Verso.

NeO3 (2008). Programa. Web.

pato, ana (2012). Literatura expandida. Arquivo e citação na obra de Dominique Gonzalez-

Foerster. São Paulo: Sesc/Associação Cultural Videobrasil.

paUls, Alan (2008). «El arte de vivir en arte». Temas lentos. Santiago de Chile: Universidad

Diego Portales, 2012, I66-184.

pressman, Jessica y otros (2015). Reading Project. A Collaborative Analysis of William

Poundstone's Project for Tachistoscope \{Bottomless Pit\}. Iowa: University of Iowa Press.

tisselli, eugenio (20II). «Why I have stopped creating e-lit». Netartery. Web.

(2015a). «Artículo 27». Urgeurge (Ultimate Reseau General intellect Emerges. Web.

(2015b). Poéticas, lo humano a flote. Entrevista (por Isaura Leonardo). Web.

ROMERO LÓPEZ, DOLORES Y AMELIA SANZ CABRERIZO (2008). Literaturas del texto al hipermedia.

Barcelona: Anthropos.

SAEMMER, ALEXANDRA (2008). «Quelques réflections sur une poétique de l'interaction».

Passaged'encres 33, I23-I29.

SÁNCHEZ GÓMEZ, LAURA (20I4). «Poéticas Digitales: el texto como imagen de una obra cinética».

Humanidades Digitales: desafios, logros y perspectivas de futuro. Janus. Anexo I, 423-434. Web. SÁNCHEZ MESA, DOMINGo (Comp.) (2004). Literatura y cibercultura. Madrid: Arco/Libros.

simón, maría victoria (2009). Presentación de Rescate. Museo de Arte Moderno de Buenos

Aires, septiembre.Web.

SPERANZA, GRACIEla (2006). Fuera de campo. Literatura y arte argentinos después de Duchamp.

Buenos Aires: Anagrama.

(2012). Atlas portátil de América Latina. Arte y ficciones errantes. Barcelona: Anagrama.

Steiner, GeORge (1978). «After the Book?». On Dificulty and other Essays. Oxford: Oxford

University Press, I87-203.

(1990). «¿Toca a su fin la cultura del libro?». Letra internacional $18,43-45$. 
vila-matas. enrique (2017, is de mayo). «Literatura expandida». El País, Café Perec. Web.

youngblood, gene (I970). Cine expandido. Buenos Aires: EDUNTREF, 2012.

\section{Sitios web de artistas}

http://motorhueso.net/

http://www.gabrielagolder.com/

\section{Sitios web generales de literatura expandida y digital}

Electronic Literature Organization: http://eliterature.org/

LitElat. Red de Literatura Electrónica Latinoamericana: http://litelat.net/

Lleom. Laboratorio de literaturas extendidas y otras materialidades: https://leom.net/

Ludión. Exploratorio latinoamericano de poéticas/políticas tecnológicas: http://ludion.org/ home.php

Museo Universitario del Chopo. Literatura expandida: http://www.chopo.unam.mx/literatura expandida.html

Sociedad Lunar. Literatura expandida: http://sociedadlunar.org/index.html 